Scholarship Repository

University of Minnesota Law School

Articles

Faculty Scholarship

2014

\title{
Hybrid Energy Governance
}

\author{
Hari M. Osofsky \\ University of Minnesota Law School, hmo8@psu.edu
}

Hannah J. Wiseman

Florida State University College of Law, hwiseman@law.fsu.edu

Follow this and additional works at: https://scholarship.law.umn.edu/faculty_articles

Part of the Law Commons

\section{Recommended Citation}

Hari M. Osofsky and Hannah J. Wiseman, Hybrid Energy Governance, 2014 U. ILL. L. ReV. 1 (2014), available at https://scholarship.law.umn.edu/faculty_articles/184.

This Article is brought to you for free and open access by the University of Minnesota Law School. It has been accepted for inclusion in the Faculty Scholarship collection by an authorized administrator of the Scholarship Repository. For more information, please contact lenzx009@umn.edu. 


\title{
HYBRID ENERGY GOVERNANCE
}

\author{
Hari M. Osofsky* \\ Hannah J. Wiseman**
}

Energy law is substantively complex and deeply fragmented. Each energy sector-including fuel extraction and pipelines, electricity generation and transmission, and transportation-has its own legal regime and federalism approach. Confusion often exists at moments of crisis about how much authority federal, state, and local regulators have in these areas. The complexity and fragmentation of energy law are particularly problematic because the energy system faces major transitions due to emerging technology, more unpredictable and extreme weather events, and public pressure for cleaner energy. Regulators struggle to: (1) manage the risks of hydraulic fracturing and deepwater drilling, which are increasingly common in light of dwindling conventional oil and gas reserves; (2) upgrade our aging electricity grid; and (3) integrate renewable energy sources onto that grid and into electricity markets.

This Article develops a novel theory of energy governance and uses it to assess how institutional innovation can help meet critical modern energy challenges. Building from our prior work arguing for a dynamic approach to energy federalism, this Article focuses on the potential of institutions that are "hybrid" by virtue of including public and private actors from several governance levels and enabling important interactions among them. Grounding its approach in interdisciplinary governance theory, it argues that these institutions have characteristics that could address structural barriers to substantive

* Hari M. Osofsky is a Professor at the University of Minnesota Law School; the 2013-14 Fesler-Lampert Chair in Urban and Regional Affairs; Director of the Joint Degree Program in Law, Science \& Technology; a Faculty Member in the Conservation Biology Graduate Program; an Adjunct Professor in the Department of Geography, Environment and Society; and a Fellow with the Institute on the Environment. Hari Osofsky would also like, as always, to thank Joshua, $\mathrm{Oz}$, and Scarlet Gitelson for their love, support, and patience.

** Hannah J. Wiseman is an Assistant Professor at the Florida State University College of Law. This Article has benefitted greatly from feedback and discussion following its presentation at Fordham Law School, Northwestern Law School, UCLA School of Law, and University of Minnesota Law School. We would like to thank Melinda Benson, Alejandro Camacho, Ann Carlson, Lincoln Davies, Dan Farber, Victor Flatt, Robert Glicksman, Alexandra Klass, Alfred Marcus, and Elizabeth Wilson for their thoughtful commentary on the draft. We also appreciate the very helpful research assistance of Kenzie Johnson and David Warden, and the excellent editorial work of Laura Meli, Jacqueline Waldman, Whitney Merrill, Andrew Barrios, and Benjamin Sunshine of the University of Illinois Law Review. 
progress in energy law, such as inadequate, divided regulatory authority, and the complexities of including key private actors in energy decision making. After introducing its new conceptual model, this Article examines several hybrid institutions with substantial regional components that are working to address the three core substantive energy challenges identified here. It analyzes their progress in meeting these challenges and how their hybrid governance approach is assisting them in doing so.

\section{TABLE OF CONTENTS}

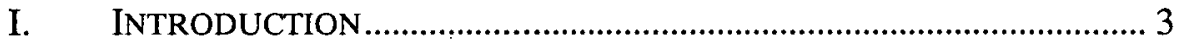

II. CONCEPTUALIZING HYBRID REGIONAL GOVERNANCE ................ 5

A. The Need for Institutional Innovation ..................................... 6

B. The Potential for Hybridity to Help Ameliorate Governance Challenges.

III. ADDRESSING RISKS AND INEQUALITY IN UNCONVENTIONAL FUEL DEVELOPMENT: REGIONAL STRUCTURES FOR CITIZEN PARTICIPATION

A. Problems of Risk and Inequality in Fuel Extraction

B. Regulatory Innovation Through Hybrid Regional Structures

1. Introducing Comprehensive Regulation and Expanding Stakeholder Involvement to Prevent and Address Risk

2. Aggressive and Inclusive Regionalism.

3. Combining Stakeholder Input and Regional Approaches to Navigate Governance Challenges

IV. ENSURING GRID RELIABILITY AS TECHNOLOGY CHANGES:

THE NERC EXAMPLE.

A. The Need to Update Grid Reliability Practices as Technology Changes

B. Regulatory Innovation Through Hybrid Regional Structures

1. Coordinating Standards Through Private Governance and Adding Public Oversight

2. Horizontally and Vertically Integrating Key Actors.

3. Maintaining Private Involvement Within Shifting Hierarchical Processes

V. INTEGRATING RENEWABLES ONTO THE GRID: EFFORTS BY REGIONAL TRANSMISSION ORGANIZATIONS

A. Challenges Facing the Integration of Renewables onto the Grid...

B. Regulatory Innovation Through Hybrid Regional Structures. 


\section{Implementing Creative Pricing Schemes and}

Prioritizing Regional Transmission Build-Out

2. Forging Horizontal and Vertical Connections.

3. Including Public and Private Actors in Multidirectional Planning Processes................................ 54

VI. BENEFITS AND LIMITATIONS OF INSTITUTIONAL HYBRIDITY ..... 55

A. Difficulties of Defining "Success" ........................................ 56

B. Substantive Assessment ........................................................ 57

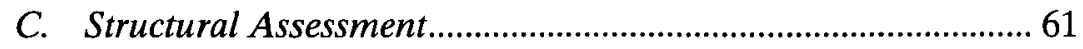

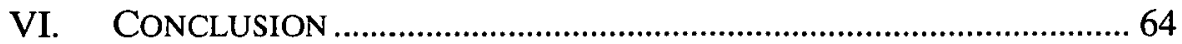

\section{INTRODUCTION}

Except when crisis hits, energy consumers prefer not to "look behind the plug." We expect that the lights will turn on, gas stations will have fuel for our cars, and our computers and iPads will charge. Energy law reflects this understanding with its two fundamental mandates: reducing fuel and electricity costs and maintaining reliable service.

As becomes clear, however, when oil pours into the Gulf, ${ }^{1}$ utilities fail to restore power rapidly after major storms, ${ }^{2}$ or the lights go out during the Super Bowl, ${ }^{3}$ what lies behind the plug is extremely messy and fragile. The energy system and the law that attempts to regulate it are substantively and structurally complex. This complexity is particularly problematic because the energy system faces a moment of major transition as regulators grapple with new technologies and public pressure for "cleaner" energy. ${ }^{4}$ Specifically, they struggle to manage the risks of hy-

1. See Nat'l Comm'n on the BP Deepwater Horizon Oil Spill \& Offshore Drilling, Stopping the Spill: The Five-Month Effort to Kill the Macondo Well (Staff Working Paper No. 6, 2010), available at http:/www.oilspillcommission.gov/sites/default/files/documents/Updated $\% 20$ Containment \%20Worki ng\%20Paper.pdf.

2. See infra Part II; PJM, OPERATIONS UPDATE: HURRICANE SANDY, available at http://www. pjm.com/ /media/committees-groups/committees/mc/20121126-webinar/20121126-reports-item-03bhurricane-sandy.ashx (2012) (noting "140 transmission lines out of service," forty offline generators, approximately five million customers without service during the peak of the problems, and observing that customer outages were "higher than both the 6/29/2012 Derecho and Hurricane Irene," while assessing the impacts of the hurricane and reporting preliminary data); Peter Applebome \& Elizabeth Maker, In Connecticut Replay, Storm Comes, Power Goes, N.Y. TIMEs, Feb. 11, 2013, at A12 (noting that "losing trees and power has been common in Connecticut in recent storms"); Nate Schweber \& Jess Bidgood, Anxiety Grows as Thousands Remain Stranded and in the Dark After Storm, N.Y. TIMES, Feb. 10, 2013, http://www.nytimes.com/2013/02/11/us/after-the-big-snowfall-the-struggle-to-digout.html?pagewanted=all\&_r=0 (noting that at one point after the storm, 650,000 customers in Connecticut, Rhode Island, and Massachusetts were without power).

3. Ken Belson, Before Game is Decided, Superdome Goes Dark, N.Y. TIMES, Feb. 3, 2013, http://www.nytimes.com/2013/02/04/sports/football/power-outage-in-superdome-delays-superbowl.html.

4. See Dennis Jacobe, Americans Want More Emphasis on Solar, Wind, Natural Gas, GalluP (Mar. 27, 2013), http://www.gallup.com/poll/161519/americans-emphasis-solar-wind-natural-gas.aspx; Press Release, Nat'l Renewable Energy Lab., Energy Department, NREL Announce New Research 
draulic fracturing and deepwater drilling, ${ }^{5}$ upgrade our aging electricity grid, respond quickly to outages ${ }^{6}$ and integrate renewable energy sources onto that grid and into electricity markets. ${ }^{7}$

Energy federalism and governance are at the heart of this struggle. Our prior article, Dynamic Energy Federalism, critiques both energy law and the scholarship that analyzes it as deeply fragmented. ${ }^{8}$ Each primary source of energy - coal, oil, natural gas, nuclear, hydropower, solar, wind, geothermal, and hydrokinetic - has its own legal regime.' Electricity, pipelines, transmission systems, and transportation are addressed separately as well. ${ }^{10}$ This fragmentation is not simply substantive; the federalism arrangements within each sector are often inconsistent and unclear. ${ }^{11}$ For example, natural gas pipeline construction is largely federalized, while new electricity transmission generally must navigate state and local land use planning. ${ }^{12}$ Moreover, confusion exists at critical momentsafter an accident or major weather event-about how much authority federal, state, and local regulators have, which creates obstacles to effectively addressing substantive challenges. ${ }^{13}$ We conclude Dynamic Energy Federalism by arguing for a holistic, systematic approach to these federalism and governance challenges that: (1) establishes adequate regulatory authority, (2) reduces overlap and fragmentation, and (3) incorporates key stakeholders appropriately.

This Article takes on the challenge of developing such an approach and, in so doing, fills a key gap in energy law and federalism scholarship. It proposes an innovative model of energy governance, using what it terms "hybrid" institutions to address substantive energy challenges more effectively..$^{15}$ Hybrid institutions combine authority from more than one level of government, whether as a formal or informal part of their structure or governance process, and also include private and public actors within the governance process. The Article specifically examines hybrid institutions with strong regional components-either multistate groupings from particular parts of the country or key stakeholders from a particular part of a state. It argues that these regional institutions' unusual position between other governance levels - for example, at a level of

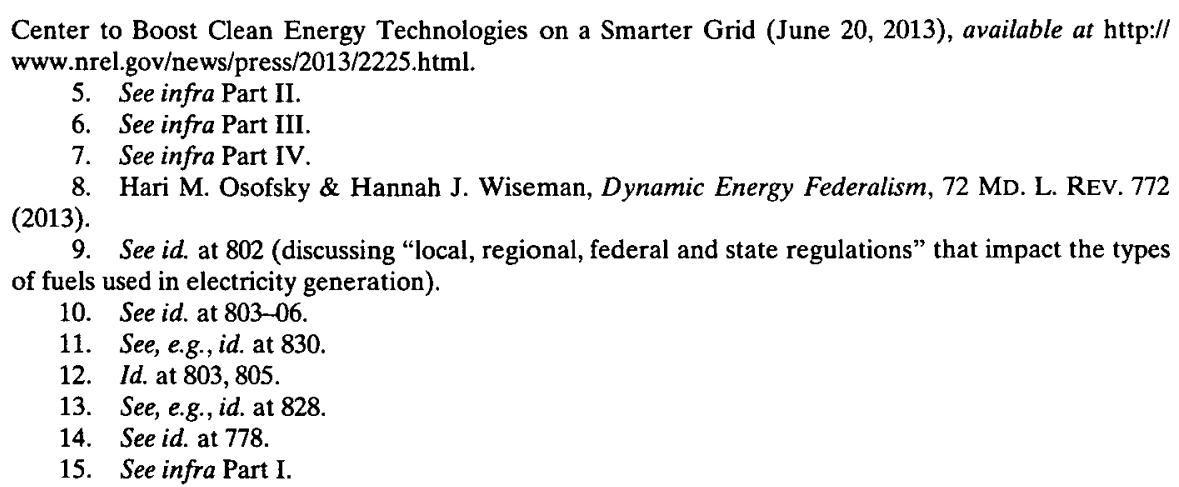


authority that is larger than states but smaller than federal-helps them serve as important bridges between the key levels of authority in energy regulation and take advantage of the many commonalities that geographic proximity brings. ${ }^{16}$

Building from the conceptual model for hybrid energy governance it proposes in Part II, this Article evaluates this governance form in action. In Parts III through V, it provides detailed case studies of three sets of innovative institutions, analyzing whether their hybrid, regional regulatory structures and approaches help them to make substantive progress within an exceedingly complex energy system. Part III examines efforts by the Delaware River Basin Commission (DRBC) and Regional Citizen Advisory Councils (RCACs) to reduce the risks of hydraulic fracturing and deepwater drilling. Part IV considers initiatives by the North American Electric Reliability Corporation (NERC) and its regional entities to maintain the reliability of the electricity grid as needed upgrades and smart grid computerization take place. Part V analyzes initiatives by regional transmission organizations (RTOs) to integrate renewable energy onto the physical grid and into energy markets. After an in-depth discussion of each set of institutions, the Article in Part V assesses the benefits and limitations of hybrid, regional governance as a strategy for energy transformation.

Through its model and case studies, this Article makes important contributions to both the energy law and federalism literatures. Theoretically, it creates a new category for analysis-hybrid energy governance - and situates this category within a holistic understanding of energy federalism and governance. Its analytical approach provides a model for how to translate dynamic energy federalism into needed institutional development. Practically, these institutional innovations are already occurring in areas critical to the future of the energy system but have not yet been analyzed in depth. This Article offers a needed assessment of how these institutional forms emerge, what they are achieving, and the benefits and limitations of their approach. This assessment could both make these institutions more effective and serve as a basis for expanding hybrid energy governance strategies into other contexts.

\section{CONCEPTUALIZING HYBRID REgIONAL GOVERNANCE}

This Part provides the conceptual grounding for the rest of the Article's detailed case studies. It first explores the need for institutional innovation to address the complex challenges facing the U.S. energy system. It focuses in particular on the governance challenges of inadequate regulatory authority, fragmented regulatory authority, and integrating key public and private stakeholders into the process appropriately. The Part then draws from interdisciplinary governance theory to explain why

16. See infra Part I. 
hybrid institutions, in theory, are a promising way to meet that need. It proposes a model of hybridity designed to meet these governance challenges through (1) interaction across levels of government and the public and private spheres; (2) regionalism, which forms a governance level between traditionally accepted levels, such as the local, state, and federal; and (3) enhanced participatory mechanisms.

\section{A. The Need for Institutional Innovation}

The energy system in the United States, which we mapped in $D y$ namic Energy Federalism, ${ }^{17}$ is never static. As that article describes in detail, this system consists of continuously interacting physical, market, and regulatory dimensions. A complex physical infrastructure of generation, sprawling transmission lines, and dense distribution networks delivers electricity to consumers. A multilevel regulatory framework both forms this physical structure and continuously remolds it, demanding or dampening new types of fuels and generation sources and requiring transmission upgrades for reliability and the accommodation of new generation. The market, in turn, heavily influences fuel choice in electric generation and decisions about where and when to build new infrastructure. ${ }^{18}$ All three parts of the system - the physical, regulatory, and market components - experience constant fluctuation as relevant technology evolves, ${ }^{19}$ electricity consumers demand change in the form of cleaner and more affordable technologies, ${ }^{20}$ and policies shift accordingly. ${ }^{21}$

These interactions within the tripartite energy system involve numerous public and private stakeholders at multiple levels of government. Understanding these interactions, and their implications for governance, requires a dynamic, holistic model of energy federalism; such a model both examines the nuances of interactions among and within levels of

17. See Osofsky \& Wiseman, supra note 8 , at 780-807.

18. See id.

19. See, e.g., John Hauer et al., Advanced Transmission Technologies, NAT'L TRANSMISSION GRID STUDY, at F-4-F-5, F9 (2002), available at http://certs.lbl.gov/ntgs/issue-6.pdf. Hauer et al. describe technologies, like flexible AC transmission systems (FACTS) that "balance the load between" certain lines and computer and communication devices called supervisory control and data acquisition (SCADA) and energy management system (EMS) technology, which provide better real-time data about electricity being demanded from the grid and available electricity generation. All of these technologies allow the grid to be operated closer to its maximum limits (capacity), but as this occurs, "knowing exactly where those limits are and how much operating margin remains becomes increasingly important." Id.

20. See, e.g., Jesse Broehl, Colorado Voters Pass Renewable Energy Standard, RenEwaBle ENERGY WORLD (Nov. 3, 2004), http://www.renewableenergyworld.com/rea/news/article/2004/11/ colorado-voters-pass-renewable-energy-standard-17736; Anthony York, Voters Reject Prop. 23, Keeping California's Global Warming Law Intact [Updated], L.A. Times PolmiCAL (Nov. 2, 2010, 11:17 $\mathrm{PM}$ ), http://latimesblogs.latimes.com/california-politics/2010/11/voters-reject-prop-23-keeping-cali fornias-global-warming-law-intact.html.

21. See, e.g., Renewable Portfolio Standard Policies, DATABase of State InCENTIVES for RENEWABLES AND EFFICIENCY (2013), available at http://www.dsireusa.org/documents/summary maps/RPS_map.pdf (showing twenty-nine states, the District of Columbia, and two territories with standards that require a certain percentage of electricity to come from renewable energy sources). 
government-local, state, national, international, and regional ones in between. The model also considers how interactions in one part of the energy system, such as regulatory efforts by regional institutions to expand transmission, relate to other parts of the system, such as transmission line owners' market-based opposition to sharing the costs of expansion. ${ }^{22}$

This Section builds upon that approach to analyze how three specific governance concerns-inadequate jurisdictional authority, related concerns of overlapping or fragmented authority, and heavy involvement of private actors in energy governance-create the need for institutional innovation. First, any institution tasked with balancing the physical, market, and regulatory aspects of the U.S. energy system will, if not carefully designed, have inadequate authority. Because the system covers a wide geographic area with areas of uneven demand-for instance, there is concentrated energy use in population centers - it often implicates local, state, regional, and federal concerns. ${ }^{23}$ Yet many processes either fail to incorporate all of the key actors or fail to give them sufficient jurisdiction over an energy problem. For example, regional transmission organizations (RTOs), which in many parts of the country govern the flow of electricity through transmission lines and operate the lines, have some authority to plan for needed interstate transmission line expansion, but individual state and sometimes municipal governments retain jurisdiction over siting. ${ }^{24}$

Second, institutional arrangements that give actors inadequate authority over a problem also may produce both overlapping legal authority and fragmentation, leading to regulatory confusion at best and inaction or inappropriate action at worst. ${ }^{25}$ Often, the lack of authority described above results from separate regulatory entities having simultaneous control. Despite many entities controlling different aspects of a problem, their jurisdiction combined is not sufficient to fully address the energy challenge. The above-mentioned example of interstate transmission siting exemplifies this difficulty with RTOs, states, and sometimes municipalities all having only a piece of the relevant authority. Challenges of fragmented and overlapping authority also arise in identifying how much each region should have to pay for the costs of building new interstate transmission lines - a process called cost allocation. As with transmission siting, FERC is involved in shaping RTOs' planning for new

22. See Osofsky \& Wiseman, supra note 8, at 807-24.

23. See id. at 776 (explaining the complex array of actors implicated in power outages).

24. See id. at $801-07$.

25. This challenge echoes the regulatory commons problem theorized by William Buzbee. This problem typically arises when impacts like aquaculture or climate change cross jurisdictional boundaries, and multiple governments have some but not full responsibility for controlling the impacts. No one government has adequate authority or incentive to address the entire problem, and this creates a regulatory commons in which regulatory gaps occur. See William W. Buzbee, Recognizing the Regulatory Commons: $A$ Theory of Regulatory Gaps, 89 IowA L. REV. 1, 22-26 (2003). 
transmission and efforts at cost allocation. ${ }^{26}$ It issues federal orders and RTO-specific conditions for how RTOs may allocate costs, for example. ${ }^{27}$ Yet individual states powerfully influence the cost allocation scheme ultimately agreed upon, and FERC, like RTOs, lacks meaningful influence in the siting of these new lines. ${ }^{28}$

The simultaneous fragmentation and overlap obscures the gaps in energy governance and complicates efforts to fully address problems, requiring each actor to fully understand the other's role and recent actions taken and then to change its own approach either to avoid redundancy or fill in gaps. This demands much of institutions already struggling to address their own complicated sphere of energy problems; expecting them to further change their behaviors to accommodate deficiencies or approaches of other actors may be too much to ask of resource-limited institutions. ${ }^{29}$

These problems of legal overlap and fragmentation also raise questions about how to structure the decision making hierarchy among the many actors involved and about how cooperative the key actors are on a particular energy issue. The multiplicity of actors within energy institutions - actors from many levels - can lead to competing hierarchies. For example, in the context of deepwater drilling, even though a National Contingency Plan ostensibly controlled the response to the BP Deepwater Horizon oil spill, states and localities asserted jurisdiction in many stages of the response efforts, ${ }^{30}$ and subgroups of federal agencies made decisions about closing fisheries and applying dispersants. ${ }^{31}$ With respect to interaction among the actors with partial authority to decide, the many parties often cooperate at one point in time and conflict at other points. For instance, states and municipalities may support an RTO decision to expand a transmission line and even to site it within their jurisdiction, but they may vehemently oppose the allocation of transmission line costs to their utility customers. ${ }^{32}$

In a final structural governance challenge, private entities often play an important role in the relevant publicly established institutional structure, which raises the potential for capture. For example, oil corporations, such as BP, are central players in spill responses, both because of the National Contingency Plan structure that includes the responsible company as a key participant in the planning and mitigation process for spills and because of their expertise and control over site access. In the contexts of electric reliability and the expansion of transmission lines,

26. See Osofsky \& Wiseman, supra note 8, at 803-05.

27. See id. at 805 (citing FERC Order No. 100-B (Order on Rehearing and Clarification, issued Oct. 18, 2012)).

28. See id.

29. See id.

30. See id. at 828 .

31. See id. at 830 .

32. See id. at 805-07. 
utilities are members of RTOs that plan for transmission; they also are members of regional entities that propose and sometimes enforce reliability standards and have an important say in these organizations' decisions. These private entities play a crucial role in providing the technical information and institutional knowledge necessary for these decisions. Utilities may best know the real threat of cyber attacks, for example, and thus the needed mechanisms to prevent such an attack, and they are highly aware of transmission constraints and needed expansion. Despite procedural safeguards against conflicts within these institutions, private entities may sometimes have too much influence within a decision making process. ${ }^{33}$

Dynamic Energy Federalism, in addition to introducing these structural challenges and their interaction with the tripartite energy system, proposes federalism principles for energy governance, which guide this Article's institutional analysis and assessment. ${ }^{34}$ Specifically, that article argues that these institutions must: (1) create needed regulatory authority, (2) reduce fragmentation of regulatory authority, and (3) provide high levels of involvement from key public and private stakeholders that allow for meaningful input without capture. These principles call for creating institutions that incorporate actors from all levels of government affected by an energy issue, address overlap and fragmentation through defining hierarchical relationships within these institutions, and better integrate public and private stakeholders.

\section{B. The Potential for Hybridity to Help Ameliorate Governance Challenges}

To explore how to design institutions in line with these principles, this Article analyzes three sets of institutions, each of which focuses on one of the substantive challenges of core energy transformation outlined in the Introduction: (1) improving risk governance in fuel extraction, (2) maintaining grid reliability in the face of changing technology, and (3) connecting more renewable energy sources to the grid. The institutions described in Parts III through V, all of which have taken steps to foster needed substantive change in the energy system, have also developed mechanisms that begin to navigate the governance challenges described in Dynamic Energy Federalism by incorporating the needed governance strategies identified there. Namely, they help to constitute adequate authority over an energy issue, address regulatory overlap and fragmentation by defining hierarchies and encouraging better and more efficient communication among actors at multiple governance levels, and include key public and private stakeholders.

33. See id. at $839-42$.

34. See id. at 778 . 
These institutions have limitations, but three structural patterns emerge as they incorporate some of these governance strategies. These patterns may provide examples for broader paths forward in energy governance that comport with the principles discussed in the previous Section, and together, they form a model for hybrid energy governance.

First, all of the institutions are, at least in part, hybrids that combine many key actors at different levels of government. To understand this aspect of hybridity, it is useful to envision different governance levels as residing along a vertical axis, from the sublocal to the international, and actors within each governance level as occupying a horizontal axis (such as state public utility commissioners acting together within an institution). Hybrid institutions vertically combine multiple levels of governance and require horizontal cooperation among a number of actors at each level, including regulated utilities. These institutions also typically include private actors either as voting members or in other participatory forms that give them power to influence outcomes; they are therefore also hybrid in their combining of public and private interests.

Our conception of hybridity is informed by recent scholarship on legal pluralism focused on how to construct institutions that can manage overlapping legal regimes and norms. Legal pluralism generally explores situations in which more than one legal and/or normative order is present, including, for example, local or community-based norms for resource development and a regulatory regime that formally limits the amount of resource that may be extracted. In the international law context in particular, global legal pluralism has created models for how this multiplicity can be institutionally managed, which include some proposals for creating hybrid institutions. ${ }^{35}$ In addition, we build from complementary work by Jody Freeman and Jim Rossi on U.S. domestic administrative law exploring agency coordination in the face of pervasive "overlapping and fragmented delegations." 36

Throughout this Article's case analysis, we consider how institutional hybridity can help to coordinate among multiple public and private orders within shared regulatory space. For instance, in the first context of managing the risks of unconventional fuel extraction, Regional Citizens Advisory Councils (RCACs) allow for informal norms of communities, nongovernmental organizations, and corporations to be brought to-

35. See, e.g., Paul Schiff Berman, Global Legal Pluralism, 80 S. CAL. L. REv. 1155 (2007) (analyzing a variety of pluralist models); see also Diane Marie Amann, Calling Children to Account: The Proposal for a Juvenile Chamber in the Special Court for Sierra Leone, 29 PEPP. L. REV. 167 (2001); Elena A. Baylis, Parallel Courts in Post-Conflict Kosovo, 32 YAle J. INT'L L. 1 (2007); William W. Burke-White, International Legal Pluralism, 25 Mich. J. INT'L L. 963 (2004); Janet Koven Levit, $A$ Bottom-Up Approach to International Lawmaking: The Tale of Three Trade Finance Instruments, 30 YALE J. INT'L L. 125 (2005); Ralf Michaels, The Re-State-Ment of Non-State Law: The State, Choice of Law, and the Challenge from Global Legal Pluralism, 51 WAYNE L. REv. 1209 (2005).

36. See, e.g., Jody Freeman \& Jim Rossi, Agency Coordination in Shared Regulatory Space, 125 HARV. L. REV. 1131, 1135 (2012). 
gether with the government-driven regulatory process. ${ }^{37}$ Or, in our third example of integrating renewables onto the electricity grid, RTOs can help harmonize the state and local land use regimes that control transmission siting with larger-scale planning processes to build new transmission lines. ${ }^{38}$

These hybrid institutions all have significant regional components, which provide the second element of our governance model. These regional structures exist between two vertical governance levels (e.g., state and federal), and they help to combine the partial authority at state and federal levels to make meaningful progress. This regional structure also pulls together multiple actors at one governance level (e.g., state); although this combining can lead to both cooperation and conflict, it enables governments to address energy issues that cross borders more effectively. This regional scaling creates a needed authority bridge between levels of government.

Regional regulation within the United States is a well-established means of drawing regulatory spaces between local, state, federal, and international authority. Broad literatures have emerged in both the law and geography fields to describe and analyze this governance approach. They consider the nature of the regional scale, its benefits and limitations, and how it interacts with other levels of government. ${ }^{39}$ We draw from this scholarship as we explore how the regional dimensions of these institutions impact their regulatory role and capacity to address governance challenges.

Third, all of the institutions not only include both private and public actors, but also provide for significant public and private stakeholder involvement in the regulatory process; they include utilities, energy companies, and other entities as voting members or key stakeholders. Although the mechanisms for input vary significantly across these entities, they form an important component of the governance process in each instance.

Recent scholarship on new governance informs the Article's assessment of how hybrid structures can be designed to include stakeholders effectively and appropriately. New governance views regulation not as solely top-down, public control by state and federal agencies with central authority, but rather as an ongoing and ever-changing relationshipoften one of negotiation and compromise-between agencies, regulated entities, and other stakeholders. Professors Kenneth W. Abbot and

37. See infra Part III.

38. See, e.g., 89 FERC 61, 285 at 19-20; see discussion infra Part V.B.2.

39. See, e.g., Robin Kundis Craig, Constitutional Contours for the Design and Implementation of Multistate Renewable Energy Programs and Projects, 81 U. CoLo. L. REV. 771 (2010); Felix Frankfurter \& James M. Landis, The Compact Clause of the Constitution-A Study in Interstate Adjustment, 34 YALE L. J. 685, 696-98 (1925); Noah D. Hall, Toward a New Horizontal Federalism: Interstate Water Management in the Great Lakes Region, 77 U. COLO. L. REV. 405 (2006); Hannah Wiseman, Expanding Regional Renewable Governance, 35 HARV. ENVTL. L. REV. 477 (2011). 
Duncan Snidal, for example, have contrasted new governance approaches with traditional ones as state-orchestrated instead of state-centered; as decentralized instead of centralized; as drawing from dispersed expertise, including business knowledge, instead of bureaucratic expertise; and as combining hard and soft law, such as elements of industry-developed standards, rather than focusing exclusively on mandatory rules. ${ }^{40}$ The institutions in the case examples have many of these qualities, which assist their role in navigating federalism and governance challenges, as explored in the following Parts.

Together, legal pluralism, regionalism, and new governance help to frame the model of hybrid energy governance proposed here: a model of hybrid institutions that include both private and public actors from state, local, and federal levels; that typically exist within a regional space between these governance levels; and that allow a number of stakeholders to participate in decision making processes in meaningful ways. As explored in the Parts that follow, the combination of these approaches within an institutional hybrid, paired with mechanisms to allow for flexibility, provide new insights. These Parts focus on examples of institutions that have followed this model as they address modern substantive energy challenges, exploring how well these governance approaches work when applied to real, complex energy problems.

\section{ADDRESSING RISKS AND INEQUALITY IN UNCONVENTIONAL FUEL DEVELOPMENT: REGIONAL STRUCTURES FOR CITIZEN PARTICIPATION}

As private actors develop new technologies ${ }^{41}$ to satisfy Americans' enduring thirst for an unlimited and uninterrupted energy supply-and, increasingly, a demand for domestic sources-onshore unconventional oil and gas development ${ }^{42}$ and deepwater drilling ${ }^{43}$ have emerged as prev-

40. Kenneth W. Abbott \& Duncan Snidal, Strengthening International Regulation Through Transnational New Governance: Overcoming the Orchestration Deficit, 42 VAND. J. TRANSNAT'L L. 501, 508-09 (2009). For additional examples of new governance approaches, see Bradley C. Karkkainen, "New Governance" in the Great Lakes Basin: Has Its Time Arrived?, 2006 MICH. ST. L. REV. 1249, 1254-55 (2006); J.B. Ruhl \& James Salzman, Climate Change, Dead Zones, and Massive Problems in the Administrative State: A Guide for Whittling Away, 98 CAL. L. REv. 59, 102-08 (2010).

41. Even technological progress in fuel extraction is far from purely private. The government subsidizes the expensive technologies needed for unconventional development through tax exemptions and other mechanisms, and it also directly funds research-often public-private ventures-through organizations like the National Energy Technology Laboratory. See, e.g., NAT'L ENERGY TECH. LAB., Obama AdMINISTRation ANNOUNCES NEW PARTNERShip ON UNCONVENTIONAL NATURAL GAS AND OIL RESEARCH (Apr. 13, 2012), http://www.netl.doe.gov/publications/press/2012/ 120413_obama_administration.html.

42. See, e.g., INTL. ENERGy AGENCY, World ENERGy OUTLOOK 49, 75-76 (2012) (describing rapidly growing U.S. shale gas and oil production, which might cause the United States to become a net exporter of fuels); U.S. ENvTl. Protection Agency, Proposed AMENdments to Air REGULATIONS FOR THE OIL AND NATURAL GAS INDUSTRY 2 (July 28, 2011), available at http:// www.epa.gov/airquality/oilandgas/pdfs/20110728factsheet.pdf (explaining that approximately 11,400 new gas wells are fractured in the United States each year and that approximately 14,000 are refractured). 
alent technologies. These have introduced new risks and new environmental justice concerns, often in rural contexts, and have pushed at the boundaries of existing energy governance. A focus on how to manage these risks and fairness concerns effectively is critical because the pressures to augment domestic supply and achieve energy independence are unlikely to decline. Even if we produced all of our fuel domestically, a scenario that has become more realistic with recent technological advances, we could not avoid the inevitable echoes of a global fossil fuel market ${ }^{44}$ and would not be immune from price swings and certain ongoing trade disputes. ${ }^{45}$ This Part focuses on possibilities for governance innovation to address the governance concerns associated with expanding domestic fuel extraction. It begins by exploring the substantive and regulatory problems arising in the context of fuel extraction and then turns to an examination of hybrid, regional institutions working to address these problems.

\section{A. Problems of Risk and Inequality in Fuel Extraction}

The combination of drilling and hydraulic fracturing to extract gas and oil from shale and other lower permeability formations (broadly described as shale gas and oil development), has expanded monumentally in recent years, ${ }^{46}$ and specific fracturing technologies have changed. Energy companies have applied larger volumes of water and, in some cases,

43. See, e.g., John M. Broder \& Clifford Krauss, U.S. in Accord With Mexico on Drilling, N.Y. TIMES, Feb. 20, 2012, http://www.nytimes.com/2012/02/21/world/americas/mexico-and-us-agree-on-oiland-gas-development-in-gulf.html (explaining that a U.S.-Mexican agreement on the regulation of offshore drilling in the Gulf might open "more than a million acres to deepwater drilling").

44. See JoHn S. DuFfield, OVER A BARREL: THE COSTS OF U.S. FOREIGN OIL DEPENDENCE 27 (2008) (noting that even if the United States did not import any oil, our "economy could still be greatly affected by developments abroad" because of the linkage between domestically produced oil and global markets-including global prices).

45. See id. Ultimately, regardless of where we produce oil and gas, these are global goods. If we extract more here and rely less on imports, we might enjoy short-term energy security by avoiding the need to intervene in foreign countries in order to secure current access to fuel. But if we remain concerned about price spikes, other countries' reliance on enemies' fuel sources, and the maintenance of a relatively steady global supply of fossil fuel for our allies, expanded domestic production may do little to change America's foreign policy stance and its interest in overseas supplies. That said, if we became a net energy exporter, this would certainly give us more bargaining power in a number of disputes and could potentially avoid some of the violent conflicts that have been associated, at least in part, with oil and gas. See, e.g., Richard J. Pierce, Jr., Natural Gas: A Long Bridge to a Promising Destination, 32 UTAH ENVTL. L. REV. 245, 251 (2012). ("The shale gas boom will also have significant beneficial effects on geopolitical conditions by, for instance: reducing Russia's leverage over Europe due to Gazprom's dominance of the European gas market, reducing Iran's leverage over India due to India's heavy reliance on energy supplies from Iran, and eliminating completely the risk that Russian President Vladimir Putin will be successful in his efforts to create a natural gas version of the OPEC cartel.").

46. See Envtl. Protection Agency, supra note 42, at 2; Hannah Wiseman, Risk and Response in Fracturing Policy, 84 U. CoLO. L. REV. 729, 735 (2013), [hereinafter Risk and Response] (describing how the number of fractured wells in Pennsylvania rose by more than three-hundred percent between 2008 and 2009); Hannah Wiseman, Fracturing Regulation Applied, 22 DUKE ENVTL. L. \& POL'Y F. 361, 362-63 (2012) [hereinafter Fracturing Regulation] (describing the first "slickwater" fracture treatment in the Barnett Shale in the 1990s). 
new chemicals to wells - particularly in unconventional formations such as shales and tight sands ${ }^{47}$ - to produce surprising quantities of domestic natural gas and oil. ${ }^{48}$ While advances in drilling and hydraulic fracturing in these formations have promised cheaper and abundant domestic supplies, they have introduced noticeable risks. Chemical spills, stored wastes, and inadequately treated wastewaters can pollute surface or underground resources. ${ }^{49}$ Improperly-constructed wells can send methane into nearby water wells during the drilling process, ${ }^{50}$ and overwithdrawals of water for fracturing can negatively impact stream flow. ${ }^{51}$ As more wells are drilled, habitats are fragmented, air pollutants increase, soil erodes and pollutes surface waters, and trucks damage roads. ${ }^{52}$

Many of these risks are local. Air pollutants from drilling and fracturing may not drift far, and neighbors typically experience the brunt of the noise and dust. ${ }^{53}$ Others, however, have both local and regional impacts. Soil erosion, chemical spills, and improper storage and disposal of wastewater can pollute waters shared by several states, and emissions of greenhouse gases from drilling and processing equipment, wastewater, and gas wells and pipelines have global effects. ${ }^{54}$

Regardless of the extent to which effects cross jurisdictional lines, many citizens have objected to what they view as an unfair distribution of

47. See Fracturing Regulation, supra note 46, at 362-63 (explaining that different technologies are used in slickwater fracturing of shales and tight sands, as compared to coalbed methane fracturing).

48. What Is Shale Gas and Why Is It Important?, U.S. Energy Info. Admin., http:// 205.254.135.7/energy_in_brief/about_shale_gas.cfm (Dec. 5, 2012) (projecting "U.S. natural gas production to increase from 23.0 trillion cubic feet in 2011 to 33.1 trillion cubic feet in 2040 , a $44 \%$ increase," nearly all of which will result from shale gas production); N.D. PETROLEUM COUNCIL, NORTH DAKOTA DEPARTMENT OF RESOURCES ANNUAL REPORT 3, 9-10 (2011), available at http:/www. ndoil.org/image/cache/NDPCAnnual092111_2.pdf (showing record numbers of new well permits issued in recent years, which, as shown by the remainder of the report, is due largely to production of oil from the Bakken Shale).

49. Despite the outpouring of attention to the potential for contamination of underground water supplies, the majority of risks appear to arise at the surface based on incidents at shale gas and tight sands sites so far. See generally Risk and Response, supra note 47, at 760 (characterizing the risks based on state enforcement of environmental regulations at shale gas and tight sands sites); Fracturing Regulation, supra note 47, at 361-67 (summarizing the risks and describing state enforcement actions at well sites).

50. See Hannah J. Wiseman \& Francis Gradijan, Regulation of Shale Gas Development, Including Hydraulic Fracturing at 49-50 n.230 (June 15, 2012) (unpublished manuscript), available at http://papers.ssrn.com/sol3/papers.cfm?abstract_id=1953547 (describing gas migration incidents located through public records requests).

51. See N.Y. Dept. OF ENVTl. Conservation, Supplemental Revised Draft ENVIRONMENTAL IMPACT STATEMENT 6-2 (2011) (describing water withdrawal impacts), available at http://www.dec.ny.gov/docs/materials_minerals_pdf/rdsgeisch50911.pdf; Wiseman \& Gradijan, supra note 5, at 71-72; Fracturing Regulation, supra note 46, at 366.

52. For a summary of many of the risks, see generally Risk and Response, supra note 46, at 779$82,794-96$.

53. Id. at 796-97; David B. Spence, Federalism, Regulatory Lags, and the Political Economy of Energy Production, 161 U. PA. L. REV. 431, 481 (2013) (observing that fracturing "can affect the air quality, water quality, and visual aspects of the nearby environment").

54. For summaries of effects and their likely geographic distribution, see Spence, supra note 53, at $480-81$. 
burdens. ${ }^{55}$ Municipalities in New York, ${ }^{56}$ Pennsylvania, and other states have banned hydraulic fracturing ${ }^{57}$ (with bans in Pennsylvania likely having only symbolic value ${ }^{58}$, and government officials have complained of their inability to adequately influence the pace and location of development. $^{59}$ Around the country, neighbors of property owners who leased mineral rights and allowed drilling and fracturing have sued, alleging groundwater contamination and other health effects. ${ }^{60}$ Some environmental groups ${ }^{61}$-indeed, even several states - have called for closer attention to risks, more precautionary regulation, and at least temporary moratoria on fracturing. ${ }^{62}$ From a market perspective, others have questioned the federal government's continued subsidization of this practice,

55. See, e.g., Eliza Griswold, The Fracturing of Pennsylvania, N.Y. TIMES MAGAZINE (Nov. 17, 2011), http:/www.nytimes.com/2011/11/20/magazine/fracking-amwell-township.html?pagewanted=all (describing some township residents' objections to fracturing and its impacts).

56. Pamela Chergotis, Highland is the Latest Town to Ban Fracking, PIKE CNTY. COURIER, (July 12, 2012), http://pikecountycourier.com/apps/pbcs.dll/article?AID=/20120712/NEWS01/120719968/ Highland-is-the-latest-town-to-ban-fracking (describing four New York towns in the Delaware River watershed that have banned fracturing); see also Anschutz Exploration Corp. v. Dryden (N.Y. Sup. 2012); Cooperstown Holstein Corp. v. Town of Middlefield (N.Y. Sup. 2012) (validating bans); Longmont, Colorado, Charter, Article XVI, $\$ 16.3$, available at http://library.municode.com/index.aspx? clientId $=14590$ (prohibiting hydraulic fracturing).

57. See supra note 56 (describing bans).

58. See 58 PA. CONS. STAT. ANN. $\$ 3304$ (a) (b) (West 2012) (providing that "all local ordinances regulating oil and gas operations shall allow for the reasonable development of oil and gas resources," shall allow well operations, may not impose conditions on oil and gas operations more stringent than limitations on other industrial uses within the local jurisdiction, and "[s]hall authorize oil and gas operations ... as a permitted use in all zoning districts"). But see Robinson Twp v. Commonwealth, 52 A.3d 463, 480 (Pa. Commw. Ct. 2012) (invalidating the preemption (under review; currently awaiting a decision by the Pennsylvania Supreme Court)).

59. See, e.g., Samuel Gallaher, Buechner InSt. For Governance, Local, Regional, ANd State Government PERSPECTIVES ON Hydraulic Fracturing-Related OIL AND GaS DEVELOPMENT, Full Report, at iv, available at http:/www.ucdenver.edu/academics/colleges/SPA/ BuechnerInstitute/Research/natgasdev/library/Documents/Government $\% 20$ Perspectives $\% 20$ on $\%$ 20Oil\%20and\%20Gas\%20Development\%20Full\%20Report\%202013\%20Gallaher.pdf (noting local officials' concerns about road damage and about the adequacy of bonds for addressing local damage).

60. See, e.g., Berish v. Southwestern Energy Prod. Co., 763 F. Supp. 2d 702, 703 (M.D. Pa. 2011); Fiorentino v. Cabot Oil \& Gas Co., 750, F. Supp. 2d 506, 508 (M.D. Pa. 2010).

61. See, e.g., Risky Gas Drilling Threatens Health, Water Supplies, NATURAL RES. DEF. CouncIL, http://www.nrdc.org/energy/gasdrilling/ (last visited Nov. 17, 2013); Lisa Sumi, Oil and Gas Accountability Project, Our Drinking Water at Risk, (2005), available at http://www.earthworksaction. org/files/publications/DrinkingWaterAtRisk.pdf.

62. See Jim Efstathiou Jr., New Jersey Lawmakers Send Christie Ban on Hydraulic Fracturing, BLOOMBERG (June 29, 2011), http:/www.bloomberg.com/news/2011-06-30/new-jersey-lawmakerssend-christie-ban-on-hydraulic-fracturing.html; Vermont First State to Ban Fracturing, CNN NEws (May 17, 2012), http://articles.cnn.com/2012-05-17/us/us_vermont-fracking_1_fracking-shale-naturalgas?_s=PM:US; MD. DEP'T OF THE ENV'T, FACTS ABOUT... THE MARCELlus Shale SAFE DRILLING INITIATIVE, http:/www.mde.state.md.us/programs/Land/mining/Non\%20Coal\%20Mining/ Documents/Shale_EO_factsheet_061011.pdf (describing a three-part study in Maryland on fracturing risks); Press Release, N.Y. DEP'T OF ENVTL. CONSERVATION, NEW RECOMMENDATIONS ISSUED IN HYDRAULIC FRACTURING REVIEW (June 30, 2011), http://www.dec.ny.gov/press/75403.html (describing New York's extensive process to review the risks of shale gas development, after which "the Department will implement a system of oversight, monitoring and enforcement"). 
arguing that it encourages and makes artificially cheap a damaging practice that already is common. ${ }^{63}$

Like shale gas and oil development, deepwater drilling and spills resulting from it take place at the outer boundaries of our technical capabilities and regulatory capacity and raise major concerns about the distribution of energy burdens. Technological developments have allowed deepwater drilling to expand dramatically in the last decade, which has brought with it the challenges of working at the high pressures and temperature differentials thousands of feet below the surface; some operations are now reaching oil as deep as 30,000 feet below the surface. ${ }^{64}$ The need to control these operations remotely from the surface paired with sometimes unstable geologic formations adds further complications. ${ }^{65}$

The 2010 BP Deepwater Horizon spill reinforced these risks. It resulted in nearly five million barrels of oil spilling into the ocean, and containment efforts included usage of an unprecedented 1.8 million gallons of dispersants, some of which were applied deeper than ever before. ${ }^{66}$ Key governmental and corporate actors struggled to contain the spill and accurately estimate the flow rate and volume of the spill, efforts that were hampered by their regulatory and physical dynamics, ${ }^{67}$ these two problems interacted as underestimation of the spill rate undercut containment efforts. ${ }^{68}$ The oil spilling out moved through currents and was affected by storms in difficult to predict ways, with the complexity of addressing the spill reinforced by the poorly understood deepwater location and dispersant use. ${ }^{69}$

63. But cf. Helen Cooper and Jonathan Weisman, Obama Seeks to End Subsidies for Oil and Gas Companies, N.Y. TIMEs (Mar. 1, 2012), http://www.nytimes.com/2012/03/02/us/politics/obamacalls-for-an-end-to-subsidies-for-oil-and-gas-companies.html.

64. Temperatures are very cold at the seabed and very hot where the oil is located. See NAT'L COMM'N ON THE BP DEEPWATER HORIZON OIL SPILl \& OFFSHORE DRILLING, DEEPWATER: THE GUlF OIL DisAster aNd THE Future OF OFFSHORE DRILLING- REPORT TO THE PRESIDENT, 48, 51 (2011), http:/www.gpo.gov/fdsys/pkg/GPO-OILCOMMISSION/pdf/GPO-OILCOMMISSION.pdf [hereinafter NATIONAL COMMISSION REPORT].

65. See id. at 21, 41-43, 45-52, 90-100; Mark A. Latham, Five Thousand Feet and Below: The Failure to Adequately Regulate Deepwater Oil Production Technology, 38 B.C. ENVTL. AFF. L. REV. $343,346-47,346$ n.20 (2011).

66. See Nat'l Comm'n on the BP Deepwater Horizon Oil Spill \& Offshore Drilling, Stopping the Spill: The Five-Month Effort to Kill the Macondo Well (Staff Working Paper No. 6, 2010), available at http://www.oilspillcommission.gov/sites/default/files/documents/Updated\%20Containment \%20Worki ng\%20Paper.pdf.; Nat'l Commission on the BP Deepwater Horizon Oil Spill \& Offshore Drilling, The Use of Surface and Subsea Dispersants During the BP Deepwater Horizon Oil Spill 1 (Staff Working Paper No. 4, 2011), available at http://www.oilspillcommission.gov/sites/default/files/documents/ Updated\%20Dispersants\%20Working\%20Paper.pdf; One Year Later Press Pack, RESTORETHE Gulf.Gov (Apr. 10, 2011, 3:27 PM), http://www.restorethegulf.gov/release/2011/04/10/one-year-laterpress-pack.

67. NATIONAL COMmission REPORT, supra note 64, at 146-47; Nat'l Comm'n on the BP Deepwater Horizon Oil Spill and Offshore Drilling, Decision-Making Within the Unified Command 12 (Staff Working Paper No. 2, 2011), http:/www.oilspillcommission.gov/sites/default/files/documents/ Updated\%20Unified\%20Command\%20Working\%20Paper.pdf.

68. NATIONAL COMMISSION REPORT, supra note 64, at 129-71.

69. Id. at 174-75, 182; see also Christopher M. Reddy et al., Composition and Fate of Gas and Oil Released to the Water Column During the Deepwater Horizon Oil Spill, PNAS, Early Edition July 
The spill deeply affected a range of communities and interests, from luxury resorts to rural fishers to low-income communities of color, which predominantly bore the burden of the waste in their municipal land dumps. ${ }^{70}$ Moreover, the ongoing ecological and human impacts of the 1989 Exxon Valdez spill reinforce the impossibility of understanding the full impacts of oil spills in their immediate aftermath, especially in the less-pristine environment of the Gulf. After the spill, diverse stakeholders raised questions about the values and structures that should be included within drilling regulation and clean-up and compensation schemes. Many political and corporate leaders argued for quickly resuming offshore drilling despite its risks - citing to jobs and economic benefits - while deeply-rooted fishing, environmental, and tourist-based interests demanded caution and improved regulatory oversight. States that had resisted offshore drilling objected to the damage caused by a disaster that they did not create, highlighting the complicated externalities that can emerge from large, risky extraction projects. As with shale gas development, a number of actors also questioned the federal government's continued subsidization of offshore unconventional drilling. ${ }^{.1}$

In both instances, these substantive risks interact with the complexities of the energy system to create acute governance challenges. The underlying federalism arrangements in these two contexts are strikingly different, however. Much of the law applicable to hydraulic fracturing is state-based-a confusing mix of common law property and statutory environmental and energy regulation ${ }^{72}$ - which raises serious issues for regionally-based operations and for the growth of this technique across the United States. In contrast, deepwater drilling is regulated largely at a federal level, but dynamics among federal agencies and between the federal entities and state and local government create difficulties. ${ }^{73}$

2011 at 1, available at http:/www.pnas.org/content/early/2011/07/15/1101242108.full.pdf+html?withds=yes; Press Release, National ScienCe Foundation, Chemical Make-up of Gulf of Mexico Plume Determined (July 18, 2011), http://www.nsf.gov/news/news_summ.jsp?cntn_id=120962\&WT .mc_id=USNSF_51\&WT.mc_ev=click.

70. Hari M. Osofsky, Multidimensional Governance and BP Deepwater Horizon Oil Spill, 63 FLA. L. REV. 1077, 1112 (2011) [hereinafter Multidimensional Governance] (citing Robert D. Bullard, Voices: Environmental Justice Communities Bear Brunt of BP's Oil Spill Waste Disposal, THE INSTTTUTE FOR SOUTHERN STUDIES (Apr. 23, 2011, 10:48 AM), http:// www.southernstudies.org/ 2011/04/voices-environmental-justice-communities-bear-brunt-of-bps-oil-spill-waste-disposal.html) (explaining that 42.3 percent of the waste went to communities that had majority people of color and that 85.1 percent went to municipalities in which the percent of people of color in the community was higher than the percentage in the county).

71. For an in-depth discussion of these concerns, see NAT'L COMM'N ON THE BP DEEPWATER HORIZON OIL SPILL \& OFFSHORE DRILLING, REPORT TO THE PRESIDENT, supra note 1; Osofsky, Multidimensional Governance, supra note 70; Hari M. Osofsky, Kate Baxter-Kauf, Bradley Hammer, Ann Mailander, Brett Mares, Amy Pikovsky, Andrew Whitney \& Laura Wilson, Environmental Justice and the BP Deepwater Horizon Oil Spill, 20 N.Y.U. ENVTL L.J. 99 (2012).

72. See Hannah Wiseman, Regulatory Adaptation in Fractured Appalachia, 21 VILL. ENVTL. L.J. 229, 243-47 (2010) (describing some of the major federal exemptions, which largely leave states with regulatory responsibilities).

73. For a detailed examination of federalism dynamics around deepwater drilling, see Multidimensional Governance, supra note 70. 
With respect to the shale gas and oil context in which hydraulic fracturing takes place, some of the effects of onshore drilling extend beyond jurisdictional borders, thus creating concerns about inadequate authority as well as fragmented and/or overlapping approaches to the issue. Drilling and fracturing rigs and other equipment at gas well sites can send air emissions beyond local or potentially state borders and can have important cumulative effects, yet the Clean Air Act does not cover all of these emissions. ${ }^{74}$ To fill this gap, some states are monitoring and regulating emissions at well sites; others are not. ${ }^{75}$ Furthermore, when well operators send drilling and fracturing wastes to wastewater treatment plants, inadequately treated wastes from these plants could pollute rivers that run through multiple jurisdictions. ${ }^{76}$ The EPA has promised to develop wastewater treatment standards for these wastes, but these will not be in place until 2014. ${ }^{77}$ In the meantime, regional river basin commissions have begun to address certain water quality problems; the Delaware River Basin Commission, for example, has proposed to require Commission approval of shale gas waste disposal through wastewater treatment plants. ${ }^{78}$ Pennsylvania, in turn, has required treatment of shale gas wastewater prior to its disposal through treatment plants, ${ }^{79}$ and has since requested that operators not send waste to any in-state treatment plants. $^{80}$

The federal government, some states, and regional commissions have attempted to regulate impacts on both air and water, but their simultaneous efforts leave gaps in authority; some harmful emissions may

74. ENVTL. Protection Agency, Proposed Amendments to Air Regulations for the Oil and Natural Gas Industry, Fact Sheet at 2, http://epa.gov/airquality/oilandgas/pdfs/20110728factsheet.pdf (noting air emissions, such as carbon monoxide, not regulated in the final rule); Oil and Natural Gas Sector: New Source Performance Standards and National Emission Standards for Hazardous Air Pollutants Reviews, EPA-HQ-OAR-2010-0505 (finalized Apr. 17, 2012), available at http://www.epa.gov/ airquality/oilandgas/pdfs/20120417finalrule.pdf (regulating volatile organic compounds from wells).

75. See generally Pa. DEP'T OF ENVTL. PROT., NORTHCENTRAL PENNSYLVANIA MARCELluS Shale SHORT-TERM AMBIENT AIR SAMPLING REPORT (2011), available at http://www.dep.state. pa.us/dep/deputate/airwaste/aq/aqm/docs/Marcellus_NC_05-06-11.pdf; Sampling Results Near Oil and Natural Gas Facilities by County, TEX. COMM'N ENVTL. QUALITY, http://www.tceq.texas.gov/ toxicology/barnettshale/samplingresults (last updated Sept. 30, 2013).

76. Letter from Shawn M. Garvin, Regional Administrator, Envtl. Prot. Agency, to Michael Krancer, Acting Secretary, Pennsylvania Dept. of Envtl. Protection (Mar. 7, 2011), available at http://www.epa.gov/region3/marcellus_shale/PADEP_Marcellus_Shale_030711.pdf (describing concerns about inadequately treated wastewater from shale gas wells).

77. Press Release, Envtl. Prot. Agency, EPA Announces Schedule to Develop Natural Gas Wastewater Standards (Oct. 20, 2011), http://yosemite.epa.gov/opa/admpress.nsf/bd4379a92 ceceeac8525735900400c27/91e7fadb4b114c4a8525792f00542001! OpenDocument.

78. Natural Gas Development Regulations, Del. River Basin Comm'n (proposed Nov. 8, 2011) (implementing $\S \S 3.3,3.6(\mathrm{~b}), 3.8,4 \mathrm{~d}, 5.2,7.1,13.1$ and 14.2(a) of Delaware River Basin Compact, Pub. L. No. 87-328, 75 Stat. 688 (1961)), [hereinafter Revised Draft of Natural Gas Development Regulations], available at http://www.nj.gov/drbc/library/documents/naturalgas-REVISEDdraftregs11081 1.pdf.

79. 25 PA. CODE $\S 95.10(\mathrm{~b})$ (2010).

80. Press Release, Commonwealth of Pennsylvania Dept. of Envtl. Protection, DEP Calls on Natural Gas Drillers to Stop Giving Treatment Facilities Wastewater (Apr. 19, 2011), available at http://www.portal.state.pa.us/portal/server.pt/community/newsroom/14287?id=\%2017071\%20\&typeid $=1$. 
remain unchecked. ${ }^{81}$ Furthermore, as all of these different authorities attempt to partially respond to a bigger problem-the broader environmental impacts caused by the thousands of new wells drilled as a result of advanced fracturing technologies ${ }^{82}$ - they may engage in overlapping, fragmented regulation that could be more efficiently conducted by one entity, such as a regional river authority or the EPA.

Deepwater drilling raises similar concerns despite a largely federally-based regime. Overlapping and incomplete authority, as well as issues of how to appropriately incorporate public and private stakeholders, arise both in offshore drilling regulation and in oil spill responses. ${ }^{83}$ For example, in the aftermath of the BP Deepwater Horizon oil spill, the National Contingency Plan (NCP) governing the response included numerous federal agencies, as well as state and local government representatives. ${ }^{84}$ Even at the federal level, however, this effort to consolidate and coordinate authority was incomplete. The Department of Energy was not included within the group even though it was very involved in the spill response. In addition, clusters of key agencies made decisions about fisheries' closures and dispersants outside of the NCP process. ${ }^{85}$ Moreover, the multiple levels of government involved in the response often added complexity. Governors early on claimed that the Stafford Act, which would give states control over the response, applied rather than the NCP. ${ }^{86}$ Particular substantive issues where smaller scale governments disagreed with the federal government also created conflict that made centralized control difficult. For instance, the Coast Guard tried to create a systematic approach to the placement of boom-physical barriers to the oil. ${ }^{87}$ But states resisted those decisions, and used their own regulatory authority and funds given to them from BP to place boom in ways that at times thwarted the Coast Guard's efforts to match barriers to the greatest risks based on tidal currents. ${ }^{88}$

Finally, effective regulation of both shale gas and oil development and offshore drilling demands highly technical data. Authorities must understand the complicated technologies used, the geologic conditions encountered thousands of feet below ground or the ocean floor, ${ }^{89}$ and the composition of the wastes created, among a number of other details, in

81. See Risk and Response, supra note 46 , at 145 (describing proposed and finalized regulations).

82. For a discussion of the likely impacts, see $i d$. at $125-26,184$.

83. For an in-depth discussion of these issues, see Multidimensional Governance, supra note 70, at $1091,1096$.

84. See NATIONAL COMMISSION REPORT, supra note 64, at 131.

85. See Decision-Making Within the Unified Command, supra note 67, at 8-9; Osofsky, supra note 70 , at 1095 .

86. Osofsky, supra note 74 , at 1092.

87. See NATIONAL COMMISSION REPORT, supra note 64 , at 153.

88. See Decision-Making Within the Unified Command, supra note 67, at 17-20.

89. See, e.g., Halliburton, U.S. SHAle Gas: AN UNCONVENTIONAL Resource, UNCONVENTIONAL CHALLENGES (2008), available at http:/www.halliburton.com/public/solutions/ contents/shale/related_docs/H063771.pdf (describing differences among the several types of shales and tight sands drilled and fractured). 
order to identify and effectively address risks. Private actors possess most of this information and therefore must be involved in the regulatory process. Because many of these private actors are large, international energy companies with sophisticated revolving-door relationships with agencies and policy makers, the risk of capture is particularly high. In the shale gas and oil context, for example, one of the major federal regulatory exemptions for hydraulic fracturing often is colloquially known as the "Halliburton loophole" 90 because of industry communications with government actors prior to the passage of the exemption. ${ }^{91}$ Similarly, following the BP Oil Spill, numerous accounts of industry influence in the well approval process showed that the Minerals Management Service cut corners in environmental review ${ }^{92}$ - in large part due to industry pressure to allow drilling to move forward quickly. This necessary but sometimes problematic inclusion of private actors within governance addresses unconventional extraction risks and demands an innovative hybrid approach, as do the authority-based challenges. The following Sections discuss how institutions have begun to implement this approach and gauge the success of these techniques in both addressing risk and overcoming governance hurdles.

\section{B. Regulatory Innovation Through Hybrid Regional Structures}

As discussed in Section III.A, demand in the United States for cheap, domestic fuels has helped incentivize energy companies' increasing reliance on risky technologies to extract these fuels. Shale gas and oil drilling and hydraulic fracturing, and offshore drilling, in particular, have emerged as dominant extraction techniques. The failed BP well in the Gulf of Mexico caused widely-dispersed pollution and sweeping economic and environmental damage, while the many stages of well development in shales have transformed communities and caused road damage, surface spills, and local air quality and water use concerns, among many other effects. ${ }^{93}$ As these technologies continue to expand, new mechanisms will be needed to control risk in a way that equitably distributes the burdens of energy development; gives individuals, local, and state governments some degree of control over the externalities of development; and incorporates a range of competing values from tourism and natural resource-based industries that demand environmental protection to rig workers who demand steady work.

This Section focuses on two institutions that have taken steps toward these goals while navigating the complexities of energy governance.

90. See, e.g., Editorial, The Halliburton Loophole, N.Y. TIMEs, Nov. 3, 2009, at A28, available at http://www.nytimes.com/2009/11/03/opinion/03tue3.html?_r=0.

91. See Hannah Wiseman, Untested Waters: The Rise of Hydraulic Fracturing in Oil and Gas Production and the Need to Revisit Regulation, 20 FORDHAM ENVTL. L. REV. 115, 181 (2009).

92. See, e.g., NATIONAL COMMISSION REPORT, supra note 64, at 228.

93. See supra Part II.A. 
Like most of the hybrid institutions described in this Article, these institutions emerged, or made substantial modifications to existing structures or rules, in response to pressing energy challenges. In the context of shale gas development, as energy companies leased minerals in anticipation of drilling and fracturing in the Delaware River watershed, ${ }^{44}$ the DRBC, an existing regional institution, proposed to expand its regulatory activities to address drilling and fracturing within its watershed. ${ }^{95}$ RCACs, in turn, serve as an important institutional response to oil spill risks, and they emerged in response to a dramatic oil spill. The Section describes each type of institution and explores how its unique structure drives its response to both substantive and structural challenges.

\section{Introducing Comprehensive Regulation and Expanding Stakeholder Involvement to Prevent and Address Risk}

The DRBC, established in 1961, was originally formed because of growing legal disputes among states within the Delaware River watershed that culminated in a 1954 Supreme Court decision allocating certain quantities of water to each state. ${ }^{96}$ Rather than continuing to litigate water disputes, the states, with Congress's approval, entered into a compact designed to address "demands upon the waters and related resources of the basin," which were then expected to "mount rapidly" as a result of rising population. ${ }^{97}$

The DRBC's recent regulations and proposals to expand RCACs into the Gulf region for input both emerged as components of efforts to rein in the risks of unconventional fossil fuel extraction through a more comprehensive discussion of risk that involved diverse stakeholders. The DRBC includes a representative from each state within the watershed, as well as one federal representative from the Army Corps of Engineers. Just as in 1961, the Commission faced growing population pressures and associated water uses and pollution. The twenty-first century introduced new threats to the river as energy companies began proposing to drill and fracture thousands of wells in the region. ${ }^{98}$ In response to rising concerns that this activity would pollute the Delaware River, the Commission-

94. But cf. Complaint at 3 New York v. United States Army Corps of Eng'rs, No. CV11-2599 (E.D.N.Y. May 31, 2011) ("Promulgation of the DRBC Regulations is expected to result in the development of between 15,000 and 18,000 natural gas wells within the Basin ....").

95. Revised Draft of Natural Gas Development Regulations, supra note 78.

96. New Jersey v. New York, 347 U.S. 995, 997 (1954) (authorizing diversions and appointing a River Master); see Carol R. Collier, The DRBC: Managing InTERSTATE WATER Conflicts THROUGH SOUND SCIENCE, ADAPTATION, AND COLLABORATION 1 (2004), available at http://www. state.nj.us/drbc/library/documents/FisheriesOpEd-July2004.pdf (noting that the Supreme Court decision "settled years of interstate conflict").

97. Delaware River Basin Compact, Pub. L. No. 87-328, 75 Stat. 688 (1961).

98. See Revised Draft of Natural Gas Development Regulations, supra note 78 (concluding that the regulations "are required for the immediate and long range use of the water resources of the Basin" and that "natural gas development projects may have a substantial effect on the water resources of the Basin"). 
which already had watershed-wide jurisdiction - proposed a sweeping set of regulations to address nearly every stage of anticipated gas development within the watershed..$^{99}$ Although old, the Commission took on a daunting new task in writing comprehensive draft regulations in areas that may push the boundaries of its jurisdiction. This effort has since stalled, and the rules have not moved forward, but they may provide an important foundation for future progress and examples for standards that states should consider implementing while awaiting regional governance..$^{100}$

The draft regulations, which the Commission proposed in 2010, would constrain the number and location of gas sites within the watershed, require erosion and sedimentation controls at the sites, require sites to comply with the strictest of two setback requirements (state or regional) from water supplies, limit the quantity of water that may be withdrawn for drilling and fracturing, detail the methods by which drilling and fracturing wastes may be disposed of, and require pre- and postdrill testing of water. ${ }^{101}$ After publishing this long set of draft regulations, the Commission solicited extensive stakeholder input and issued revised regulations, ${ }_{103}^{102}$ but it does not appear that the rules will be approved in the near future. ${ }^{103}$

The proposed regulations would address risks, as well as the equity of risk distribution, in several important ways. First, by limiting the timing and quantity of water withdrawals for fracturing and preventing withdrawals that would overly reduce stream flow, ${ }^{104}$ they would ensure that discrete communities did not bear the brunt of water-based impacts; depending on the surface water available, gas companies likely would have to separate withdrawals over time and spatially in order to avoid causing concentrated impacts in one area. Further, the regulations would give citizens claiming contamination from drilling and fracturing a powerful causal tool that many currently lack: by requiring water quality surveys prior to drilling and fracturing, the regulations would establish base-

99. Id.

100. Id.; Press Release, Del. River Basin Comm'n; DRBC Postpones Vote on Draft Natural Gas Regulations, (Oct. 7, 2011), available at http:/www.state.nj.us/drbc/home/newsroom/news/approved/ 20111007_newsrel_naturalgas.html (showing a stalled final vote, which did not later occur); "Fracking" Proposal Currently Lacks Sufficient Health and Safety Protections, STATE OF DELAWARE (Nov. 17, 2011), http://news.delaware.gov/2011/11/17/drbc_fracking/ (showing a pledged vote of "no" on the proposed regulations-a vote that then did not occur); State of N.Y. v. Army Corps of Eng'rs, 896 F. Supp. 2d 180 (E.D.N.Y. 2010) (addressing the State of New York's objection to the DRBC regulations-its argument that the proposed regulations required full National Environmental Policy Act review - and finding a lack of standing); infra notes 114-15 and accompanying text.

101. Revised Draft of Natural Gas Development Regulations, supra note 78, at 47-84.

102. Id.; Comments on Dec. 2010 Draft Natural Gas Regulations, DEL. RIVER BASIN COMM'N, http://www.nj.gov/drbc/programs/natural/draftregs-dec2010_comments.html.

103. See supra note 100; infra notes 134-36 and accompanying text.

104. Revised Draft of Natural Gas Development Regulations, supra note 78, at 52 . In addition to including minimum passby flow requirements, the regulations propose that a "withdrawal or diversion must not have a significant adverse effect or interfere with upstream or downstream dischargers ... wetlands, or aquatic life." Id. 
line levels of pollutants from which post-drill pollution could be compared. ${ }^{105}$ Finally, by regulating most stages of the drilling and fracturing process, the regulations better anticipate the many risks of development, although they still omit several important stages.

In the offshore oil context, RCACs emerged in response to a much more immediate threat than the potential for the drilling of new wells. This regulatory hybrid occurred in the aftermath of the Exxon Valdez spill, and many have called for similar institutions in the Gulf region following the BP Deepwater Horizon spill. ${ }^{106}$ One concern that arose after the Exxon Valdez spill was the capacity for key stakeholders to have a meaningful voice in the decision making process regarding oil tanker and spill management. The Oil Pollution Act of $1990,{ }^{107}$ passed in response to that spill, established a statutory basis for the creation of two RCACsone in the Prince William Sound region and the other in the Cook Inlet region - and guidelines for their membership to ensure diverse representation of important constituencies. A settlement with the key corporate actor Exxon funded these RCACs, adding a private component to this governmental response. ${ }^{108}$

The Cook Inlet RCAC, with thirteen members that represent local governments, native groups, and other groups impacted by the 1989 oil spill, has focused its efforts on improved spill prevention and response for the Inlet, including monitoring waters for signs of pollution. ${ }^{109}$ The Prince William Sound RCAC, which has nineteen members, similarly represents key constituencies that were impacted by the 1989 oil spill and have an important stake in regional oil pollution prevention and marine

105. Id. at 60 (requiring surface water testing prior to development).

106. See NATIONAL COMMISSION REPORT, supra note 64, at 1; Zygmunt J.B. Plater, Learming from Disasters: Twenty-One Years After the Exxon Valdez Oil Spill, Will Reactions to the Deepwater Horizon Blowout Finally Address the Systemic Flaws Revealed in Alaska?, 40 ENVTL. L. REP. 11,041, 11,045-46 (2010); Harlan Kirgan, Biloxi Beach Event to Call for Citizen Group to Monitor Oil and Gas Activities in Gulf of Mexico, GulfLIVE.COM (June 24, 2011, 6:56 AM), http://blog.gulflive.com/ mississippi-press-news/2011/06/biloxi_beach_event_to_call_for.html.

107. Oil Pollution Act of 1990, Pub. L. No. 101-380, 104 Stat. 484 (codified as amended in scattered sections of 33 U.S.C., 43 U.S.C., and 46 U.S.C. (2012)).

108. Felicia Barnes, Regional Citizen Advisory Councils: Their Role in Oil Spill Prevention and Response, 24 GEO. INT'L ENVTL. L. REV. 169, 170 (2012); see Plater, supra note 106, at 11,046 (citing 33 U.S.C. \$ 2732(d)); Zygmunt J.B. Plater, Facing a Time of Counter-Revolution-The Kepone Incident and a Review of First Principles, 29 U. RICH. L. REV. 657, 700-01 (1995); William H. Rodgers, Jr., The Most Creative Moments in the History of Environmental Law: "The Whats," 2000 U. ILL. L. REV. 1, 2223 (citing an E-mail from Zygmunt Plater, Professor, Bos. Coll. Law Sch., to William H. Rodgers, Professor, Univ. of Wash. Sch. of Law (Feb. 2, 1998) (on file with the University of Illinois Law Review)); George J. Busenberg, Regional Citizens' Advisory Councils and Collaborative Environmental Management in the Marine Oil Trade of Alaska (unpublished manuscript), available at http:/citation.allacademic.com//meta/p_mla_apa_research_citation/0/4/1/6/7/pages $41678 / \mathrm{p} 41678-1 . \mathrm{php}$ (studying the two advisory councils' impacts on policy change); About Us, COOK INLET REGIONAL CITIZENS ADVISORY COUNCIL, http://www.circac.org/index.php?option=com_content\&view=article \&id=1\&Itemid=9 (last visited Nov. 17, 2013) [hereinafter About Us, CoOK]; About Us, PRINCE WILlIAM SOUND REgIONAL CITIZENS' ADVISORY COUNCIL, http:/www.pwsrcac.org/about/ (last visited Nov. 17, 2013) [hereinafter About Us, PRINCE].

109. About Us, COOK, supra note 108. 
protection. ${ }^{110}$ In addition to its establishment through the OPA, the Prince William Sound RCAC is governed by a contract with the Alyeska Pipeline Service Company, which operates the trans-Alaska pipeline and the Valdez terminal. ${ }^{111}$ This contract provides funding so long as oil continues to flow through the pipeline (initially $\$ 2$ million a year and currently $\$ 3.4$ million a year), protects the RCAC's independence, and provides it with particular responsibilities. ${ }^{112}$

The work of these councils has included numerous environmental and oil spill response research initiatives. For example, the Prince William Sound RCAC's responsibilities include: "review[ing], monitor[ing], and comment[ing] on [Alyeska's] . . . oil spill prevention and response plans, environmental protection capabilities, and actual and potential environmental impacts of terminal and tanker operations;" commenting on and participating in "monitoring and assessment of environmental, social, and economic consequences of oil-transportation activities, including comments on the design of measures to mitigate the impacts of oil spills and other environmental effects of terminal and tanker operations;" and increasing "public awareness of Alyeska's oil spill response, spill prevention and environmental protection capabilities, as well as the actual and potential environmental impacts of terminal and tanker operations." 113

\section{Aggressive and Inclusive Regionalism}

In taking first steps toward controlling the risk of unconventional oil and gas development and of oil spills, the DRBC and RCACs have relied primarily upon existing or newly formed regional structures. These regional approaches have helped these institutions navigate the horizontal and vertical dimensions of the energy system by pulling together several levels of government within a single decision making process and encouraging horizontal cooperation among actors residing at parallel jurisdictional levels, such as towns, states, and tribes.

In proposing a sweeping set of regulations to address fracturing and drilling in its watershed, the DRBC has developed a new, heightened form of regionalism, in which it would serve as arbiter among conflicting state regulations, the filler of federal regulatory gaps, and the fixer of risks of regional proportion. Specifically, it has proposed relatively stringent regulations that are, arguably, not directly rooted in a compact requirement. The Compact empowers the DRBC to "[e]stablish standards of planning, design, and operation of all projects and facilities in the basin which affect its water resources, including without limitation, thereto,

110. About $U s$, PRINCE, supra note 108.

111. Id.

112. Id.

113. Id. 
water and waste treatment plants"114 and to "assume jurisdiction to control future pollution and abate existing pollution in the waters of the basin" after investigation and a public hearing. ${ }^{115}$ Several industry groups have questioned the authority of the Commission to interpret its jurisdictional mandate so broadly, however. ${ }^{116}$

Despite lingering questions about the scope of DRBC authority and the effectiveness of the draft regulations, the use of a regional forum to control the risks of drilling and fracturing in the watershed may be a necessary tool for navigating the structural challenges of federalism in this context. Entities within the Delaware River Basin operate in a complicated jurisdictional space: states and municipalities (to a very limited extent) have authority over land use, and the state controls certain water withdrawals, the siting and drilling of oil and gas wells, and waste disposal practices for these wells. ${ }^{17}$ In applying environmental regulations to these wells and their wastes, states also must comply with some federal laws; when well operators send wastes to a wastewater treatment plant, for example, the federal Clean Water Act requires the plant to provide assurances to its state permitting authority that it will be able to adequately treat these wastes. ${ }^{118}$

The proposed authority of the DRBC over gas well permitting would tread upon many of these local, state, and federal powers, and its regulations both navigate these governance levels and establish a new one for this context. Through its regulations, the institution explains that compliance with state law will in some cases satisfy DRBC requirements but lists the regional requirements that must be followed even in the event of conflict; ${ }^{119}$ it also highlights certain federal rules with which gas companies must comply, such as conducting a natural resources inventory with endangered species studies before obtaining Commission approval to withdraw water. ${ }^{120}$ The regulations further call for a stateregional collaboration in carrying out the new requirements, enlisting

114. DEL. CODE ANN. tit. 7, §6501 (1953).

115. Id.

116. See, e.g., Marcellus Shale Coalition, MSC: Draft DRBC Regulations Duplicative, Exceed Body's Legal Authority, Apr. 13, 2011, http://marcelluscoalition.org/2011/04/msc-draft-drbcregulations-duplicative-exceed-body $\%$ E2\%80\%99s-legal-authority/.

117. See DEL. CODE ANN. tit. 7, § 6501 (1953) ("WHEREAS, the water resources of the basin are presently subject to the duplicating, overlapping and uncoordinated administration of some 43 state agencies, 14 interstate agencies and 19 federal agencies which exercise a multiplicity of powers and duties resulting in a splintering of authority and responsibilities ...."); New York's Role in the Delaware River Basin Commission, DEP'T ENVTL. CONS., http://www.dec.ny.gov/lands/48454.html (last visited Oct. 22, 2013) (describing voting powers and the role of the individual state parties).

118. See Letter from Shawn Garvin, Regional Administrator, EPA, to Michael Krancer, Secretary, PADEP (May 12, 2011), available at http:/www.epa.gov/region3/marcellus_shale/pdf/ letter/krancer-letter5-12-11.pdf (noting the need for certification to show that new wastes can be treated); $c f ., 33$ U.S.C. $\S 1317$ (1977) (requiring new pretreatment standards in order "to insure that any source introducing pollutants into a publicly owned treatment works, which source would be a new source subject to section 1316 of this title if it were to discharge pollutants, will not cause a violation of the effluent limitations established for any such treatment works").

119. DEL. RIVER BASIN COMM'N, supra note 78, at 5.

120. Id. at 22 . 
state agencies to implement all of the regional requirements for well construction and operation. ${ }^{121}$ The DRBC itself would issue water withdrawal permits and approve plans for wastewater disposal, and it would fund these new regulatory activities through various permitting and water withdrawal fees. Through this scheme, the DRBC relies on existing regulations from several governance levels while inserting new, independent regional authority between these two levels.

Unlike the DRBC, which has long regional roots, RCACs are a more recent regional innovation and have more diverse members, including key representatives of citizens and interest groups. Despite these differences, the Councils follow a similar path to the DRBC in navigating governance levels while addressing unconventional fuel extraction risks. As independent regional bodies, they comment on oil spill prevention plans and drilling designs that are ultimately approved by the federal government and also develop and provide direct monitoring and enforcement. Although the boards lack the formal regulatory authority enjoyed by the DRBC, many of their members wield considerable clout and have the potential to both influence federally approved plans and bring strategies learned in the regional forum back to their own governments. The Cook Inlet RCAC Board of Directors, for example, has thirteen members, including representatives of the cities of Anchorage, Kenai, Homer, Seldovia, and Kodiak, the Kodiak Island Borough and the Kenai Peninsula Borough, and interest group representatives that include Alaska native organizations, its state chamber of commerce, environmental organizations, recreational groups, commercial fishing groups, and aquaculture associations. The Board also has ten ex officio members from the U.S. Coast Guard, U.S. EPA, U.S. Forest Service, U.S. Bureau of Land Management, U.S. Bureau of Ocean Energy Management, NOAA, Alaska Department of Environmental Conservation, Alaska Department of Natural Resources, and Alaska Division of Homeland Security \& Emergency Management. ${ }^{122}$

The Prince William Sound RCAC has a similar membership configuration. Its bylaws establish nineteen voting members, which include villages and cities, as well as nongovernmental entities that represent Alaska Natives, conservation, tourism, commercial fishing, and aquaculture. ${ }^{123}$ Specific members include: the Alaska State Chamber of Commerce, Alaska Wilderness Recreation \& Tourism Association, Chenega Bay, Chugach Alaska Corporation, Cordova District Fishermen United, Kodiak Village Mayors Association, Oil Spill Region Environmental Coalition, Port Graham Corporation, Prince William Sound Aquaculture

121. Id. at 5 (noting that in accordance with the Compact, "the Commission will utilize and employ existing offices and rely upon agencies of the State of New York and the Commonwealth of Pennsylvania in their respective states in lieu of separately administering the construction and operation of individual natural gas wells and well pads").

122. Id.

123. About Us, PRINCE, supra note 108. 
Corporation, Tatitlek, the cities of Cordova, Homer, Kodiak, Seldovia, Seward, Valdez, and Whitter, the Kenai Peninsula Borough, and the Kodiak Island Borough. ${ }^{124}$

By including a variety of locally-, regionally-, state-, and federallybased actors within a regional entity, the RCACs provide another important example of a hybrid institution that addresses a critical energy governance challenge while navigating vertical and horizontal axes. Indeed, because these regional institutions were newly formed in response to a specific concern, rather than emerging out of an old regional structure that did not anticipate the risks of unconventional development, they may have more success than the DRBC in addressing potential conflicts among the many governance levels involved in the councils.

\section{Combining Stakeholder Input and Regional Approaches to Navigate Governance Challenges}

Applying risky technologies to shales thousands of feet below dry land or the ocean floor involves a massive industrial operation with risks that could cross many jurisdictional boundaries. While incidents at drilled and fractured wells have primarily had localized effects, aquifer pollution from oil and gas wastes and air pollution can extend beyond the well site. As the BP oil spill demonstrated, catastrophic events can have national impacts, sending tarballs onto distant beaches and wastes to local landfills thousands of miles from the spill. ${ }^{125}$

Activities with these types of broad impacts can create regulatory voids over which no one entity asserts authority. In Pennsylvania, for example-a DRBC member state in which gas drilling and fracturing has boomed-the EPA worried that municipal treatment plants operating under federal Clean Water Act permits were not adequately treating fracturing wastes, ${ }^{126}$ and the state, which was responsible for implementing the Act, initially resisted this claim. ${ }^{127}$ Although the state has since responded, it has in some cases encouraged out-of-state disposal, thus potentially shifting the problem elsewhere rather than fully addressing it. ${ }^{128}$ The DRBC has proposed to fill this gap, at least for wells within its

124. Member Entities, PRINCE, supra note 108.

125. See Brian Handwerk, BP Oil Spill's Sticky Remnants Wash Up Sporadically on Gulf Beaches, NATL. GEOGRAPHIC, Mar. 22, 2012, http://news.nationalgeographic.com/news/energy/2012/03/120322gulf-oil-spill-tar-balls-wash-up-on-beaches/.

126. See Letter from Shawn M. Garvin, Reg'l Adm'r, EPA Region III, to Michael Krancer, Acting Sec'y, Penn. Dep't of Envtl. Prot. (Mar. 7, 2011), available at http://www.epa.gov/region3/marcellus _shale/PADEP_Marcellus_Shale_030711.pdf.

127. Letter from Michael Krancer, Acting Sec'y, Penn. Dep't of Envtl. Prot., to Shawn M. Garvin, Reg'l Adm'r, EPA Region III (Apr. 6, 2011), available at http://www.epa.gov/region03/marcellus shale/Shawn_Garvin_Letter-April_6_2011.pdf.

128. See Deep Injection Wells: How Drilling Waste is Disposed Underground, STATE IMPACT NPR, http://stateimpact.npr.org/pennsylvania/tag/deep-injection-well/ (last visited Oct. 22, 2013) ("Much of the frack water produced in Pennsylvania gets trucked to Ohio, which has more disposal wells. Water can also be treated at private treatment facilities."). Note, however, that a larger percentage of wastewater is now reused within Pennsylvania. PENN STATE Extension, Marcellus 
watershed, by requiring that gas companies obtain approval from the Commission before disposing of wastes and demonstrate treatability. ${ }^{129}$

The DRBC, in writing regulations that may address inadequate authority and create interesting new hierarchies, also has strengthened the bottom-up element of the regulatory process. In proposing a comprehensive new regulatory regime for one type of energy extraction, the DRBC has gone to great lengths to incorporate stakeholder inputproviding a notice of proposed rulemaking in the Federal Register, receiving and responding to more than 69,000 comments, holding three public hearings at different locations, and delaying the release of draft regulations in response to the outpouring of comments. ${ }^{130}$

In addition to the specter of regulatory gaps in the area of unconventional shale gas, several levels of government may claim jurisdiction over the problem, thus potentially creating overlapping and conflicting policies or hierarchical disputes. In Pennsylvania, for example, municipalities have attempted to zone out drilling and fracturing or place strict substantive limits on development activity despite state preemption. ${ }^{131}$ Leaving most authority to the state provides regulatory uniformity and predictability, but it may create gaps in regulation; enforcement officials cannot be everywhere at once, and there is a risk-perhaps higher (or lower) than at other governance levels - that capture by certain stakeholders will prevent or weaken certain needed regulations. Beyond municipal-state conflicts, regional and state authority over water withdrawals in Pennsylvania also has created confusing overlap. ${ }^{132}$

The regional set of regulations proposed by the DRBC addresses concerns about hierarchical conflicts and overlap. With respect to hierarchy, if the regulations are implemented, municipalities in the watershed may benefit from them despite lacking independent regulatory authority over gas drilling; they could advocate for strict implementation of

Shale Wastewater ISSUES IN PENNSylvania-CurRent and EMERging TReatment and DISPOSAL TECHNOLOGIES 5 (2011), available at http://cce.cornell.edu/EnergyClimateChange/Natural GasDev/Documents/PDFs/marcellus_wastewater_fact_sheet\%5B1\%5D.pdf.

129. DEL. RIVER BASIN COMM'N, supra note 78, at 84.

130. Del. RIVER BASIN COMM'N, supra note 78; Press Release, DEL. RIVER BASIN COMM'N, DRBC Postpones November 21 Special Meeting, (Nov. 18, 2011), available at http://www.nj.gov/

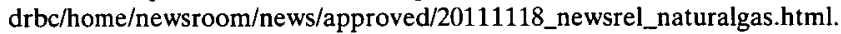

131. See 58 PA. CONS. STAT. $§ 3304$ (2013) (preempting a variety of local regulations) (found unconstitutional by Robinson Tp. v. Pennsylvania., 52 A.3d 463 (Pa. Cmmw. Ct.2012) (awaiting decision by the Pennsylvania Supreme Court)); Susan Phillips, Public Utility Commission Rejects Pittsburgh's Fracking Ban, STATE IMPACT NPR., (Sept. 11, 2012, 6:05 PM), http://stateimpact.npr.org/pennsylvania/ 2012/09/11/public-utility-commission-rejects-pittsburghs-fracking-ban/ (also discussing a PUC opinion against one county's drilling regulations). Note that these opinions will not be fully resolved until the Pennsylvania Supreme Court decides whether Pennsylvania's Act 13 is constitutional.

132. Cf. Penn State University, Marcellus Education Fact Sheet: Water WITHDRAWALS FOR DEVELOPMENT OF MARCELlUS SHALE GAS IN PENNSYLVANIA 4 (2010), available at http://pubs.cas.psu.edu/FreePubs/pdfs/ua460.pdf ("Companies must obtain the necessary state approvals as well as those of the applicable river basin commission. (In areas not covered by a river basin commission, applications for well drilling and water management plans go entirely through DEP.)"). 
the regulations within their territory, for example. The regulations also clarify regulatory overlap in water withdrawal approvals, although they do not eliminate them. They provide, for example, that a gas company proposing to withdraw water from a stream must obtain approval for its water intake design from the Executive Director of the DRBC, the host state, and several federal agencies. ${ }^{133}$

The proposed regulations, although taking regionalism to a new level through their detailed control of many risks, also have substantial flaws. In an example of iterative cooperation and conflict not always producing regulatory results, after participating in the drafting process, Delaware announced that it would vote against the proposed revised rules, citing the inadequacy of the rules for environmental protection. ${ }^{134}$ New York, in turn, sued the federal representative on the DRBC and other federal agencies, arguing for federal review of the regulations. ${ }^{135}$ Although the process was inclusive-eliciting more than 69,000 of stakeholder comments - a number of stakeholders similarly objected to the adequacy of the final regulations. ${ }^{136}$ In the meantime, other regional commissions, such as the Susquehanna River Basin Commission, have allowed drilling and fracturing within their watersheds with regulations that tend to focus only on water withdrawals, ${ }^{137}$ thus potentially subjecting certain areas to unfair levels of environmental burdens. This not-yetresolved conflict, which has resulted in less regulation of risks, suggests that even institutions structurally positioned to bring stakeholders together may not be able to create consensus and achieve regulatory results.

Oil spills can create even more confusion, gaps and overlap, and conflict in governance. For example, as noted above, when the Coast Guard attempted to implement a comprehensive policy for placing oilcontaining boom on the ocean after the BP spill, states insisted on fol-

133. DEL. RIVER BASIN COMM'N, supra note 78, at 58.

134. See Susan Phillips, As Delaware Announces No Vote on DRBC Regulations, Monday's Meeting in Doubt, STATE IMPACT NPR, (Nov. 17, 2011, 7:14 PM), http//stateimpact.npr.org/pennsylvania/ 2011/11/17/as-delaware-sets-to-vote-no-on-drbc-regulations-mondays-meeting-in-doubt/.

135. Complaint at 1, New York v. U.S. Army Corps of Eng'rs, 896 F. Supp. 2d 180 (E.D.N.Y. 2012) (No. CV11-2599).

136. See, e.g., We Are on the Road to Victory! Delaware River Basin Commission Cancels Fracking Vote!, RIVERKEEPER (Nov. 18, 2011), http:/www.riverkeeper.org/news-events/news/safeguarddrinking-water/frackinggas-drilling/drbc-cancels-fracking-vote/.

137. SusquehanNa River Basin COMm'n, FREQUently Asked Questions 2 (2012), available at http:/www.srbc.net/programs/docs/NaturalGasFAQ_20120323_140574v1.pdf (noting that "SRBC does not regulate the capture, storage, transport, treatment, recycling or disposal of frac lluid wastewater-known as flowback - from natural gas drilling and hydraulic fracturing (hydrofracing)" but that state agencies fill this role). Additionally, "SRBC's member states have the lead responsibility for regulating gas well drilling, including construction of drilling pads and access roads, water storage impoundments, well construction, and hydraulic fracturing (hydrofracing)..." Id. SRBC does not directly regulate these activities; state agencies fill this role. Id. Consumptive water use "approval specifics the maximum daily quantity of consumptive water use; metering, monitoring and reporting requirements; daily monitoring of quantities; sources of water transported to and from the site; and the fate of flowback and produced fluids in the first 30 days after hydraulic fracturing." $I d$. 
lowing their own boom placement programs. ${ }^{138}$ This conflict was further complicated by private actors' involvement in placing booms and implementing other spill response efforts. Many parties had stakes in the response, and the hierarchy of governance response was not always clear, creating the threat of unnoticed gaps in response as well as unproductive or conflicting overlap. ${ }^{39}$ RCACs, which bring together private actors and public entities from a range of governance levels to comment on spill response plans, could conceivably help to avoid these problems in the future.

Although existing RCACs are top-down in their creation (by federal statute), these institutions also allow for bottom-up input and action by bringing together local, state, regional, tribal, and federal actors with fragmented and potentially overlapping jurisdiction over oil spills. Their participants include both public and private entities, and the Prince William RCAC has a contractual arrangement with a key corporation in the region. ${ }^{140}$ They thus constitute a regional, hybrid approach to governance that helps important participants play a constructive role in a complex regulatory process.

Assessments of the RCACs' work thus far both document their successes and indicate areas for improvement. Most promisingly, Professor George Busenberg concludes that "the councils have operated as institutional learning arrangements (by promoting the application of new ideas and information to policy decisions in this system)."141 Busenberg finds that the differential funding of the two RCACs resulted in varying capacities, but that both councils have increased their ability to affect policy reforms by collaborating with other institutions. ${ }^{142}$ Zygmunt Plater recommends that other deficiencies in the RCACs need to be addressed, however, both in these entities and in any others that are created; specifically, he highlights lack of subpoena power, the need to negotiate annual funds with industry, and co-optation of council members as significant barriers to RCAC effectiveness and independence. ${ }^{143}$ Plater's critique highlights the regulatory capture concern that arises with significant private involvement in these hybrid regulatory structures.

Although DRBC and RCACs operate in different contexts and diverge in their specific regulatory roles, they share in common the hybridi-

138. See Decision-Making Within the Unified Command, supra note 67, at 17.

139. See id.

140. See Busenberg, supra note 108, at 5.

141. Id. at $18-19$.

142. See id. at 18-20.

143. See Plater, supra note 106 , at 11,046. Plater's subsequent article that builds on this shorter piece provides a more detailed analysis of citizens' councils, praising their accomplishments and analyzing challenges that they have faced. See Zygmunt J.B. Plater, The Exxon Valdez Resurfaces in the Gulf of Mexico ... and the Hazards of "Megasystem Centripetal Di-Polarity," 38 B.C. ENVTL. AFF. L. REV. 391, 409-15 (2011). For analysis of RCACs that summarizes the additional scholarly literature, see Mackenzie M. Consoer, Risk Governance within Complex and Uncertain Environments: A Retrospective Analysis of the Regional Citizens' Advisory Councils in Alaska (May 8, 2012) (unpublished manuscript) (on file with authors). 
ty and regional focus that characterizes the institutional arrangements analyzed in this Part. In both cases, their unique structure and positioning allows them to make some progress in addressing both the substantive and governance challenges discussed in Part I. They produce new regulatory strategies for risk reduction that reflect significant input from the people and entities that their approaches will affect. Despite these accomplishments, though, neither entity has had unmitigated success. As discussed further in Part VI's assessment of success, states' critiques of the DRBC and Plater's RCAC concerns reflect genuine questions about whether regulations are accomplishing enough and the extent to which the RCACs'structure and process adequately prevents private capture.

\section{ENSURING GRID RELIABILITY AS TECHNOLOGY CHANGES: THE NERC EXAMPLE}

As U.S. fuel extraction has dramatically changed and introduced new challenges, our secondary energy system-comprised of electricity generation, transmission, and distribution-also has experienced major transformations. ${ }^{144}$ These changes have been particularly acute with respect to the choice of fuels for electricity generation and the need to update and maintain a complex, aging transmission grid, as well as to ensure that an increasingly digitized system of generation and transmission is not compromised by cyber attacks. ${ }^{145}$ This Part focuses on these challenges and the possibilities for governance innovation to address them. It begins by discussing the reliability challenges that arise as technology changes and then analyzes ways in which NERC has implemented hybrid governance strategies to address these issues.

\section{A. The Need to Update Grid Reliability Practices as Technology Changes}

Three large regional mazes of wires form the U.S. grid, including the Western, Texas, and Eastern Interconnects - with the Eastern and Western Interconnects covering large portions of Southern Canada. ${ }^{146}$

144. Cf. Am. SOCIETy of Civil EngineERs, FaIlure to ACT: The ECONOMIC IMPACT OF CURRENT INVESTMENT TRENDS IN ELECTRICITY INFRASTRUCTURE 4 (2011), available at http://www. asce.org/uploadedFilcs/Infrastructure/Failure_to_Act/SCE41\%20report_Final-lores.pdf (noting improvements in energy infrastructure due to recent investments but noting the need for more investment "to further reduce the incidence of service disruptions" and the need to "adopt new technologies and to meet the demands of a growing population and evolving economy over the next 30 years").

145. NAT'L. INST. STANDARDS \& TECH., INTRODUCTION TO NISTR 7628 GUIDELINES FOR SMART GRID CYBER SECURITY 3 (2010), available at http:/www.nist.gov/smartgrid/upload/nistir7628_total.pdf ("While integrating information technologies is essential to building the Smart Grid and realizing its benefits, the same networked technologies add complexity and also introduce new interdependencies and vulnerabilities.").

146. See Learn More About Interconnections, OfFICE OF ElEC. Delivery \& ENERGy RELIABILITY, http:/energy.gov/oe/recovery-act/recovery-act-interconnection-transmission-planning/ learn-morc-about-interconnections (last visited Oct. 26, 2013). 
Within each of these three large networks of wires, which tend to be separated from each other due to historical grid development, regional institutions operate and maintain their portion of the interconnect. ${ }^{147}$ If a small failure occurs within any one of these interconnects, an entire region can experience severe power interruptions. ${ }^{148}$ The reliability mandate faced by transmission operators in the United States and Canada therefore imposes a seemingly impossible task: operators must provide a good instantaneously to all consumers at the full quantity demanded without interruption, all the while constantly balancing demand with the quantity of generation available to ensure a steady voltage in the wires. ${ }^{149}$ Seemingly benign incidents such as squirrels chewing through wires and more classic interruptions from computer-based or physical sabotage of the grid can cause massive system outages. ${ }^{150}$

Smart grid initiatives at federal, state, and local levels-paired with efforts to bring renewables onto the grid-have monumentally expanded the difficulty of maintaining grid reliability. Policy makers and scholars use the term "smart grid" in many different ways, but it generally refers to the use of computers, greater interconnection among generators and electricity users, and information flow to make the energy system more efficient, reliable, and responsive. ${ }^{151}$ Specifically, through smart grid efforts, transmission operators have begun to install computers to better isolate certain distribution areas - thus preventing widespread blackouts $^{152}$ - and to relieve congestion at certain points within the grid. ${ }^{153}$ These operators also have expanded communications among grid users and connected more grid components, allowing utilities to automatically shut down certain large electricity users during periods of peak demand, for example. ${ }^{154}$ In addition, as more renewable generators request grid

147. Id.

148. See U.S. DeP'T OF ENERGY, NATIONAL TRANSmisSion GRID STUdy 2 (2002), available at http:/energy.gov/sites/prod/files/oeprod/DocumentsandMedia/TransmissionGrid.pdf (describing instantaneous system-wide outages).

149. See Osofsky \& Wiseman, supra note 8, at 824-37.

150. See, e.g., Jon Mooallem, Squirrel Power!, N.Y. Times, Aug. 31, 2013 http://www.nytimes.com/ 2013/09/01/opinion/sunday/squirrel-power.html?_r=0 (cataloging reports of squirrels causing clectricity outages).

151. See, e.g., S. Massoud Amin \& Bruce F. Wollenberg, Toward a Smart Grid, IEEE POwER \& ENERGY MAGAZINE, Sept./Oct. 2005, at 34 (explaining the term and proposing strategies for achieving the goal of a smarter and more resilient grid).

152. See, e.g., Litos STRATEgIC COMMC'N, THE SMART Grid: AN INTRODUCTION 34, available at http://energy.gov/sites/prod/files/oeprod/DocumentsandMedia/DOE_SG_Book_Single_Pages\%281\% 29.pdf (describing the Beach Cities Microgrid, which will be able to "isolate from the utility seamlessly with little or no disruption to the loads within it and seamlessly reconnect later," and to do so "during a major grid disturbance").

153. See, e.g., Liz Enbysk, Transmission Upgrades Coming on Strong: Michigan the Latest with $\$ 90$ Million for $A B B$ Technology, SMART GRID NEwS (Feb. 23, 2012), http:/www.smartgridnews.com/ artman/publish/Delivery_Transmission/Transmission-upgrades-coming-on-strong-Michigan-the-latestwith-90-million-for-ABB-technology-4501.html .UmyHz_ksmPs (describing "dynamic voltage support" technologies deployed in Michigan to both improve regional reliability and accommodate wind power).

154. See, e.g., Demand Response, CAL. PUB. UTILS. Comm'N http://www.cpuc.ca.gov/PUC/energy/ wholesale/01a_cawholesale/MRTU/06_demandresponse.htm (last modified Dec. 9, 2008) (defining 
interconnections, utilities have begun to add new computer technologies to the grid to allow for faster plug-in and coordination of electricity supply. ${ }^{155}$ As a result of enhanced interconnection, these operators and their regulators also must address potential reliability concerns raised by introducing more intermittent sources. ${ }^{156}$

On a smaller level, smart meters installed in homes, depending on their level of intelligence, allow utilities to remotely control homes' airconditioning or heating systems, which again helps to create more load and to avoid major spikes in demand. ${ }^{157}$ Smart metering and real-time pricing of electricity allow customers to better control their electricity use by reducing demand during peak periods. ${ }^{158}$ These innovations can particularly benefit low-income customers - if they have access to the technology that is sometimes distributed inequitably, and if they have the luxury of deciding when to use larger or smaller amounts of electricitygiving those most vulnerable to price changes in an inelastic good valuable control over use decisions. ${ }^{159}$

The smart grid, which has enhanced the ability of intermittent renewable sources to connect to the grid and has introduced computers to a number of other physical grid components, is an important transformation. Yet increased reliance on computers expands the opportunities for grid sabotage and thus reliability failures; $;{ }^{160}$ indeed, China and other

real-time telemetry as "two-way real-time communication of energy usage"); Demand Response Regulation Market, PJM, http://pjm.com/markets-and-operations/demand-response/dr-regulationmarket.aspx (last visited Oct. 6, 2013) (describing participants who opt to allow very short-term changes in the quantity of electricity that flows to them in order to regulate "the stability of the power system" and explaining that these participants must have "real-time telemetry" capabilities).

155. See, e.g., ALSTOM, INTEGRATING RENEWABLE ENERGY RESOURCES 2 (2011), available at http://www.alstom.com/Global/Grid/Resources/Documents/Integrating\%20Renewable\%20Energy\%2 OSources.pdf (describing a "Renewable Operation Portal" that uses computer technology to, for example, respond "automatically to current power balance changes").

156. JiM BLATCHFORD, CAL. INDEP. SYS. OPERATOR, CAISO PARTICIPATING INTERMITTENT RESOURCE PROGRAM FOR WIND GENERATION 11, available at http://www.uwig.org/seattlefiles/ blatchford.pdf (explaining that "energy production [from wind] is unpredictable day ahead, hour ahead, and from minute to minute"). See Part II.C for further discussion of intermittency.

157. See, e.g., Earn Bill Credits by Cycling Your Central AC, COMED, https://www.comed.com/ home-savings/rebates-incentives/pages/central-ac-cycling.aspx (last visited Oct. 26, 2013) (describing automated air-conditioner cycling using a wireless signal).

158. See, e.g., The Benefits of Smart Meters, CAL. Public UTILs. Comm'N, http://www.cpuc.ca.gov/ PUC/energy/Demand+Response/benefits.htm (last modified Mar. 30, 2013) (noting that that smart metering "provides customers with greater control over their electricity use when coupled with timebased rates, increasing the range of different pricing plans available to customers and giving them more choice in managing their electricity consumption and bills"); Matthew L. Wald, 'Smart' Electric Utility Meters, Intended to Create Savings, Instead Prompt Revolt, N.Y. TIMES, Dec. 13, 2009, http://www.nytimes.com/2009/12/14/us/14meters.html (noting complaints about inaccurate meters and the higher rates necessary to recoup the costs of installing the meters, as compared to the longer-term payoffs in electricity use reductions). But see Rebecca Smith, Smart Meter, Dumb ldea?, WALL ST. J., Apr. 27, 2009, http://online.wsj.com/article/SB124050416142448555.html (noting the cost of installing the metering infrastructure).

159. On the other hand, low-income customers may benefit the least from enhanced demand controls; even if they could program a dishwasher to run at midnight rather than $6 \mathrm{PM}$, they may not have this luxury. A parent returning home from a third job at $11 \mathrm{PM}$ needs clean dishes.

160. See, e.g., Energy Delivery Systems Cybersecurity, ENERGY.GOV, http://energy.gov/oe/ technology-development/energy-delivery-systems-cybersecurity (last visited Oct. 26, 2013) ("Energy 
countries have hacked into U.S. utility computers to warn them of their abilities to interfere with the system. ${ }^{161}$ In addition, greater information flow enabled by the smart grid raises a host of privacy issues for consumers and businesses; smart grid data, if collected in the very granular form that allows for fine-tuning of energy usage, can reveal the nuances of appliance use, including even which movie someone has chosen to watch. ${ }^{162}$

As smart grid projects add more computers to transmission and distribution lines, the overarching mandate of reliability is threatened on multiple fronts. Different reliability concerns affect different local utilities - and even states - in different ways. Certain areas face few hacking threats, yet they are very concerned about technical failures of computers. ${ }^{163}$ Because the grid is interconnected, a failure by any one entity to adequately address its particular reliability concern would represent a major gap in authority. Furthermore, even for areas facing similar reliability concerns, such as hacking, without coordinated governance, there would be a threat that each utility or state would create a different reliability standard. These standards likely would have some elements in common - thus creating potentially repetitive and inefficient regulatory overlap, but they also could contain very different standards. This approach would create confusing, and potentially conflicting, requirements for large utilities operating in several regions. Because utilities often are regional or national in scope, demand for common standards could emerge, leading to hierarchical conflicts among states or utilities as they fought for the prioritization of their standards.

The early, national coordination of reliability standards through the public-private reliability organization NERC has addressed many of these governance problems that otherwise would have emerged in the reliability context, as discussed in Part IV.C. below. The addition of federal (FERC) oversight of NERC in 2005 further coordinated the many entities that write and enforce reliability standards under the NERC umbrella and clarified authority, with FERC having the power to approve or reject new standards and to review all enforcements of reliability stand-

delivery systems include control systems, the brains that operate and monitor our energy infrastructure. Two examples of such systems are the Supervisory Control and Data Acquisition (SCADA) and the Distributed Control Systems (DCS). Most early SCADA system designs did not anticipate the security threats posed by the integration of advances in computers and communication such as off-theshelf software and operating systems, public telecommunication networks, and the Internet. Energy delivery systems have become more productive and efficient, but the energy sector is faced with an unprecedented challenge in protecting systems against cyber incidents and threats.").

161. Siobhan Gorman, Electricity Grid in U.S. Penetrated by Spies, Wall ST. J., Apr. 8, 2009, http://online.wsj.com/article/SB123914805204099085.html.

162. For a discussion of smart grid and privacy issues, see H. Russell Frisby, Jr. \& Jonathan P. Trotta, The Smart Grid: The Complexities and Importance of Data Privacy and Security, 19 COMMLAW CONSPECTUS 297 (2011).

163. See discussion of cyber security issues and threats at N. AM. ELEC. RELIABILITY CORP., RELIABILITY CONSIDERATIONS FROM THE INTEGRATION OF SMART GRID, 69-80 (2010), available at http://energy.gov/sites/prod/files/oeprod/DocumentsandMedia/SGTF_Report_Final.pdf; NAT'L. INST. STANDARDS \& TECH., supra note 145. 
ards. ${ }^{164}$ This coordination still leaves room for confusion and possible hierarchical conflicts as new reliability standards are proposed, though.

Moreover, even with the benefits of this coordination, a third governance challenge emerges around potential regulatory capture. As evidenced by NERC's long history of private governance, industry involvement in regulating electric reliability is essential. Thousands of private utilities own the bulk of generation and transmission ${ }^{165}$ and understand the highly technical aspects of connecting to and operating the grid, including, for example, maintaining a relatively constant voltage in the wires despite fluctuating electricity generation and demand. Their participation in the formation and even the enforcement of the standards is therefore key; FERC cannot be everywhere at one time to monitor the behavior of each grid-connected entity, nor does it have all of the information necessary to write fully effective reliability standards. Yet leaving the very entities that profit from electricity generation and grid operation to write the standards necessary for grid reliability could be dangerous. These entities might be tempted to cut corners when standards prove particularly expensive.

These and other concerns introduce new challenges to a system of grid reliability that has operated without public control for decades, forcing innovation within an already unique public-private governance scheme. The following Section analyzes these developments and the extent to which they address substantive and structural challenges facing grid reliability.

\section{B. Regulatory Innovation Through Hybrid Regional Structures}

As utilities that operate transmission lines have struggled to keep pace with the transition to a "smarter," more computerized grid with greater integration of renewables, an old institution with a recently added federal governance structure has helped to maintain grid reliability and security. This institution, the North American Electric Reliability Corporation (NERC), has expanded and formalized a long-used privatepublic governance structure to help the grid adapt to change. The following Section explores how NERC's evolution has shaped its approach to both substantive and structural aspects of this challenge.

164. N. AM. ElEC. RELIABILITY CORP., ENSURING RELIABILITY OF THE BULK POWER SYSTEM 1 (2012), available at http:/www.nerc.com/AboutNERC/Documents/NERC\%20One\%20Pager\%20 DEC12.pdf (discussing NERC's progress in drafting new reliability standards).

165. Mason Willrich, Electricity Transmission Policy for America: Enabling a Smart Grid, End-toEnd. 7 (Energy Innovation, working Paper No. 09-003, 2009), available at http://web.mit.edu/ ipc/research/energy/pdf/EIP_09-003.pdf (noting in 2009 that IOUs "serve almost $75 \%$ of America's electricity customers and that "[o]wnership of America's electric power industry is divided among about 3100 separate entities"). 


\section{Coordinating Standards Through Private Governance and Adding Public Oversight}

Transmission operators first addressed the complex demands of grid reliability through various private governance systems, which arose in response to pressing grid reliability concerns, including major blackouts. In the 1960 s, utilities across the country formed a committee to produce "criteria and guides" for reliability operations, and certain regional groups produced reliability guides ${ }^{166}$ More serious coordination began in 1968, after "the largest blackout to date" occurred in 1965; following that blackout, utilities created a more formal organization called the National Electric Reliability Council, or NERC ${ }^{167}$ (now the North American Electric Reliability Corporation). NERC, whose members included transmission line owners, individual electricity users, and state regulatory commissions, among others, created eight subdivisions. These regional entities (REs) proposed (and still do propose) reliability standards to NERC and took core responsibility for enforcing them, as they also still do. ${ }^{168}$ These reliability standards require, for example, that utilities regularly trim vegetation around wires, identify critical cyber infrastructure and how to secure it, and maintain "contingency reserve" generation to back up failed generation. ${ }^{169}$ REs enforce these standards by imposing penalties on individual utility members, and NERC hears appeals from utilities claiming unfair enforcement. ${ }^{170}$

Where RTOs and ISOs were formed to operate the grid and the electricity and transmission services markets, regional entities were often housed within them, but they had (and continue to have) separate mandates, with the RTO focusing on operations and the RE on maintaining reliability. Where RTOs and ISOs have not been formed, the RE is an independent quasi-private institution that answers to NERC and ensures reliability within its portion of the grid. ${ }^{171}$

This complex system of private governance operated for four decades before the federal government intervened in 2005, adding a new governance layer and forcing partial publicizing of NERC..$^{172}$ This gov-

166. N. AM. EleC. Reliability CORP., HISTORY of NERC 2 (2012), available at http://www. nerc.com/AboutNERC/Documents/History_Dec12.pdf.

167. The Energy Policy Act of 2005, 16 U.S.C. $\$ 824 \mathrm{e}(4)$ (2006).

168. Compliance \& Enforcement, N. AM. ELEC. RELIABILITY CORP., http://www.nerc.com/pa/ comp/Pages/default.aspx (last visited Oct. 27, 2013) ("NERC relies on the Regional Entities to enforce the NERC Reliability Standards with Bulk-Power System owners, operators, and users through approved regional delegation agreements.").

169. See Standards, N. AM. ElEC. RELIABILITY CORP., http://www.nerc.com/pa/stand/pages/ default.aspx (last visited Oct. 27, 2013).

170. Compliance \& Enforcement, supra note 168 ("If resolution cannot be achieved at the regional level, NERC maintains an appeals process to hear disputes.").

171. For maps showing that regional entities and RTOs/ISOs do not always overlap, Regional Entities, N. AM. ElEC. RELIABILITY CORP., http://www.nerc.com/AboutNERC/keyplayers/Pages/ Regional-Entities.aspx (last visited Oct. 27, 2013); ISO/RTO COUNCIL, ISO RTO Operating Regions, http://www.isorto.org/site/c.jhKQIZPBImE/b.2604471/k.B14E/Map.htm (last visited Oct. 27, 2013).

172. 16 U.S.C. $\$ 824$ o(b)-(c) (2005). 
ernance change once again occurred in response to a massive grid reliability failure - the "worst blackout ever" on August 14, 2003. ${ }^{173}$ The Energy Policy Act of 2005 directed FERC to approve an electric reliability organization (ERO) to ensure grid reliability, and it gave FERC oversight authority. ${ }^{174}$ Congress also required that reliability standards be mandatory; FERC could directly enforce these standards, with fines up to $\$ 1$ million daily, and would review all regional entity and NERC enforcement actions. ${ }^{175}$

NERC subsequently applied to be the ERO and was approved by FERC in 2006. ${ }^{176}$ NERC's mission, which is to ensure an adequate, uninterrupted supply of electricity throughout the United States and much of Canada, ${ }^{177}$ remains the same despite the addition of this layer of federal governance. To fulfill this mandate, NERC is to propose reliability standards to FERC and enforce these mandatory standards; FERC can reject or revise standards that it deems inadequate in addition to rejecting or revising NERC enforcement decisions-or conducting enforcement itself. ${ }^{178}$ NERC continues to engage eight regional entities in both the standard writing and enforcement process; indeed, like states sometimes do in a federal system, REs perform much of NERC's work proposing reliability standards and enforcing them. ${ }^{179}$ Canadian governments also individually have entered into memoranda of understandings with the "new NERC" to confirm that it will continue to govern reliability within their provinces. ${ }^{180}$

Before and after its approval as the ERO for America and parts of Canada, NERC has been relatively successful in proposing updated standards to address new security issues inherent to the smart grid and the interconnection of thousands of new renewable sources to the grid. In developing a "Critical Cyber Asset Identification" standard, for example, NERC noted that "[b]usiness and operational demands for managing and maintaining a reliable Bulk Electric System increasingly rely on Cyber Assets supporting critical reliability functions and processes to communicate with each other, across functions and organizations, for services and data" which enhances the risk of damage to these assets. ${ }^{181}$

\footnotetext{
173. N. AM. ELEC. RELIABILITY CORP., supra note 163.

174. 16 U.S.C. $\$ 824$ o(b)-(c).

175. N. Am. EleC. Reliability CORP., Milestones: NERC Reliability STANDARds 1 (2007), available at $\mathrm{http} / / / \mathrm{www}$. nerc.com/files/standardsmilestones.pdf.

176. Id.

177. N. Am. EleC. Reliability CORP., http://www.nerc.com/ (last visited Oct. 27, 2013).

178. Scott Grover, FERC Guidance Order Shows Inter-Agency Tension, 23 NAT. RESOURCES \& ENV'T., 61, 61, 63 (2009) (describing FERC as "the final arbiter on the enforcement of reliability standards").

179. N. AM. ElEC. Reliability CORP., supra note 163.

180. Id.

181. N. AM. Elec. Reliability CORP., Cyber Security-Critical Cyber Asset IDENTIFICATION 1 (2011), available at http://www.nerc.com/files/CIP-002-4.pdf (last visited Aug. 24, 2013).
} 
Thus, while more computers are added to the grid to draw in more generation sources, connect more portions of the grid to even out demand, and improve reliability, these additions can threaten the very reliability they aim to improve. To address this challenge, NERC has proposed and FERC has approved a variety of cyber-specific reliability standards. ${ }^{182}$ They require nearly all entities associated with the grid, including generators, transmission line operators, regional entities, regional transmission organizations, and others to identify and list all of their "critical cyber assets" associated with infrastructure that supports grid reliability. ${ }^{183}$

The standards further mandate that personnel with access to these assets have special training and security awareness, ${ }^{184}$ that entities associated with the grid implement security management controls for cyber assets, and that utilities develop a Cyber Security Incident Response Plan, ${ }^{185}$ among other measures. NERC also is updating standards for grid sabotage reporting in response to stakeholder requests for clarification of the events that count as sabotage and comments on the difficulty of certain sabotage reporting. ${ }^{186}$ One update includes a requirement that cybersecurity incidents be reported within an hour of the event having been recognized. ${ }^{187}$ Between 2008 and 2013, FERC and NERC have issued more than 800 notices of penalty for cyber-related violations. ${ }^{188}$ NERC, with the help of FERC, also has addressed new renewable interconnections - issuing thirteen notices of penalty for violations of facilitybased reliability standards at wind farms during this time period. ${ }^{189}$

Major grid reliability challenges remain as renewable generators continue to request interconnection and grid computer technologies expand, thus increasing cybersecurity threats. A recent Bloomberg survey of fourteen utilities found, for example, that utilities "are able to prevent [only] 69 percent of known cyber strikes against their systems."190 Furthermore, recent studies suggest that professional hackers hired by the

182. See generally N. AM. ElEC. RELIABILITY CORP., CYBER SECURITY STANDARDS TRANSITION GUIDANCE (2013), available at http://www.nerc.com/files/cyber_security_standards_transition_ guidance.pdf.

183. See generally N. AM. ELEC. RELIABILITY CORP., supra note 181.

184. N. Am. Elec. Reliability CorP., Cyber SeCurity-PERsonnel and Training 1-2 (2011), available at http://www.nerc.com/files/CIP-004-4.pdf.

185. N. AM. ElEC. RELIABILITY CORP., CYBER SECURITY -SECURITY MANAGEMENT CONTROLS 1-2 (2011), available at http://www.nerc.com/files/CIP-003-4.pdf; N. AM. ElEC. RELIABILITY CORP., Cyber SECURITY-INCIDENT REPORTING AND RESPONSE PlanNING, 1-2 (2011), available at http://www.nerc.com/files/CIP-008-4.pdf.

186. N. AM. ElEC. RELIABILITY CORP. STANDARD DEVELOPMENT TIMELINE 5 (2012), available at http://www.nerc.com/docs/standards/sar/EOP-004-2_redline_to_initial_ballot_2012Apr24_Rev1.pdf.

187. Id. at 24.

188. See Searchable Notice of Penalty Spreadsheet, N. AM. ELEC. RELIABILITY CORP., http://www. nerc.com/pa/comp/Pages/Enforcement-and-Mitigation.aspx (follow "For the Searchable Notice of Penalty Spreadsheet click here" hyperlink) (last visited Oct. 27, 2013).

189. Id.

190. Brian Wingfield, Power-Grid Cyber Attack Seen Leaving Millions in Dark for Months, BloOMBerG (Jan 31, 2012, 11:00 PM), http://www.bloomberg.com/news/2012-02-01/cyber-attack-onu-s-power-grid-seen-leaving-millions-in-dark-for-months.html. 
Chinese government have infiltrated numerous computers of energy utilities and pipelines, ${ }^{191}$ and President Obama has issued a cybersecurity executive order in an attempt to fix stubborn challenges in this area. ${ }^{192}$ While substantial problems remain, NERC's historic and recently updated institutional approach to developing and enforcing reliability standards provides useful examples in navigating both structural and governance-specific challenges of an energy transformation.

\section{Horizontally and Vertically Integrating Key Actors}

Among energy institutions, NERC presents a unique hybrid form. Although NERC itself is technically "private," it exhibits nearly all of the typical elements of a public governance system: its board follows strict bylaws for voting and membership procedures; it develops standards by following the private procedural rules established by the American National Standards Institute; ${ }^{193}$ its standards are backed by the threat of high penalties (now as high as $\$ 1$ million daily), which it enforces; and it contains subentities (regional entities, or REs) that implement many of its rule-writing and enforcement responsibilities. ${ }^{194}$ NERC therefore resembles a private "national" government, which enlists "states" to implement its policies through a cooperative governance scheme. These statetype entities, however, are regional in nature; most REs are responsible for maintaining reliability in several states and are governed by a board of directors comprised of executives from each utility and other state members within the RE's territory. ${ }^{195}$

Following the addition of FERC's federal oversight to a onceprivate organization, NERC has largely maintained its private federalist structure. Its Board of Trustees, which makes most final governance decisions, such as the approval of reliability standards before they are sent to NERC, includes managing partners in private equity and other financial firms, senior executives of energy companies, former law firm partners, and former directors of municipally-owned utilities, among others. ${ }^{196}$ The Board of Trustees governs hundreds of entities, including

191. See David E. Sanger et al., Chinese Army Unit Is Seen as Tied to Hacking Against U.S., N.Y. TIMES, Feb. 18, 2013, http://www.nytimes.com/2013/02/19/technology/chinas-army-is-seen-as-tied-tohacking-against-us.html?pagewanted=all\&_r=0 (describing an early release of a report by Mandiant that identifies the hacking problem but noting that "China's defense ministry has denied that it is responsible for initiating attacks").

192. Exec. Order No. 13,636, 78 Fed. Reg. 11,739 (Feb. 12, 2013).

193. N. AM. ELEC. RELIABILITY CORP., supra note 169.

194. Milestones: NERC Reliability Standards, supra note 175.

195. See, e.g., About FRCC, FL. RELIABILITY COORDINATING COUNCIL, INC., https://www.frcc. com/AboutUs/default.aspx (last visited Oct. 27, 2013).

196. Board of Trustees, N. AM. ELEC. RELIABILITY CORP., http://www.nerc.com/gov/bot/Pages/ default.aspx (last visited Oct. 27, 2013). 
transmission line owners and operators, power marketers, and generators, among others. ${ }^{197}$

The Board and Regional Entities do not operate on their own, however. A "registered ballot body" consisting of utility representatives and individuals votes and comments on proposed NERC standards, ${ }^{198}$ and a committee of "sector representatives" directs the trustees' daily operations-selecting the trustees and voting on their bylaws and budgets, for example. ${ }^{199}$ Two sector representatives also participate in the NERC Standards Committee, which "oversees the drafting of NERC reliability standards";200 NERC's board of trustees ultimately approves or rejects the standards following a vote by thousands of ballot members, as described in more detail below. "[A]ny person or entity with an interest in the reliable operation of the North American bulk power system" may become a member of $\mathrm{NERC}^{201}$ and may petition to be a sector representative..$^{202}$

Unique horizontal and vertical "governance" relationships are an important part of the structure of this complex organization. Regional entities pull together utilities from various states on their boards of directors. Utilities and public utility commissions from many states ${ }^{203}$ also horizontally interact within NERC's registered ballot body as they propose and comment on reliability standards. Vertically, similar intertwining of governance relationships emerges. As introduced in Part II, NERC has an unusual number of governance layers, from individual members who may propose reliability standards through regional entities, to NERC's Board of Trustees (a national private entity), to FERC, which reviews and approves or rejects proposed standards and enforcement actions. Along both these vertical and horizontal axes, a mix of public and private actors interact in a variety of complicated ways, as described in the following section.

197. N. AM. Elec. Reliability CORP., APPENDIX 3D: Registered Ballot BoDy CRITERIA (2013), available at http://www.nerc.com/FilingsOrders/us/RuleOfProcedureDL/Appendix_3D_ BallotBodyCriteria_20140701.pdf (describing the many entities eligible to be in the Registered Ballot Body); Registered Ballot Body, N. AM. ELEC. RELIABILITY CORP., https://standards.nerc.net/rbb.aspx (last visited Oct. 27, 2013) (listing the active members).

198. Key Players, N. AM. ElEC. ReliABILITY CoRP., http:/www.nerc.com/AboutNERC/key players/Pages/default.aspx (last visited Oct. 27, 2013).

199. Member Representatives Committee (MRC), N. AM. EleC. Reliability CoRP., http://www. nerc.com/gov/bot/MRC/Pages/default.aspx (last visited Oct. 27, 2013).

200. Standards Committee (SC), N. AM. ELEC. RELIABILITY CORP., http://www.nerc.com/comm/ SC/Pages/default.aspx (last visited Oct. 27, 2013).

201. Members, N. AM. ElEC. RELIABILITY CORP., http://www.nerc.com/gov/Pages/Members.aspx (last visited Oct. 27, 2013).

202. Id.

203. Registered Ballot Body, supra note 197. 


\section{Maintaining Private Involvement Within Shifting Hierarchical Processes}

NERC's standards development process perhaps best exemplifies the specific governance interactions that add nuance to the vertical and horizontal dimensions of grid governance. It demonstrates both bottomup and top-down hierarchies, and within these hierarchies, interesting patterns of cooperation and conflict emerge, such as the development of "consensus" and minority reliability standards that are proposed to NERC's Board of Trustees. ${ }^{204}$ This process is also a powerful example of public-private governance, with utilities, electricity users, and public utility commissioners all playing central roles in standards development.

Regarding hierarchy, the standards development process has maintained a grassroots theme despite the recent addition of a federal layer. NERC writes both nationwide and regional reliability standards - all of which are ultimately approved by FERC. ${ }^{205}$ The process for proposing and approving both is similar, and the regional standard-writing process for one regional entity ${ }^{206}$ is explored here as an example.

NERC allows "any member of NERC, including any member of a regional reliability organizations, regional entity, or group within NERC" or "any entity (person, organization, company, government agency, individual, etc.) who is directly and materially affected by the reliability of the North American Bulk Power Systems" to request the "development, modification, or withdrawal of a reliability standard." 207 Those entities requesting a regional standard in the territory of the regional entity apply to a regional entity committee that assigns drafting responsibilities to a task force: the Standards Drafting Team. ${ }^{208}$ This team posts a draft on the regional entity website and allows thirty days of comments. ${ }^{209}$ It then summarizes the comments, revises the standard accordingly, posts the revision, and schedules a vote by interested parties. ${ }^{210}$ The team prepares a consensus draft following a vote on the standard, along with a minority report for unresolved significant issues; this report includes any appeals by interested parties who claim that the standard violates the standards procedure manual. ${ }^{211}$

Voting segments for proposed regional reliability standards include a public-private mix of interested parties from the transmission, genera-

204. See, e.g., Sw. Power Pool, Southwest Power Pool Regional Entity Standards DEVELOPMENT PROCESS MANUAL 15-16 (2007), available at http:/www.spp.org/publications/ SPP\%20RE\%20Standards\%20Development \%20Process\%20Manual.pdf.

205. N. AM. ElEC. Reliability CORP., STANDARd PROCESSES MANUAL 12 (2013), available at http://www.nerc.com/comm/sc/Documents/Appendix_3A_StandardsProcessesManual.pdf.

206. SW. POWER POOL, supra note 204

207. Id. at 10. Other regional entities follow similar processes to the Southwest Power Pool's

Regional Entity's procedure for proposing reliability standards.

208. Id. at 13 .

209. Id. at 14 .

210. Id. at 14-15.

211. Id. at $15-16$. 
tion, power marketers/brokers, distribution/load serving entities, and end user/public interest group sectors. ${ }^{212}$ The Markets and Operations Policy Committee (MOPC) reviews the recommended standard and makes an advisory vote; it also may request revision or standard termination. ${ }^{213}$ The regional entity's board of directors and members committee then both review the standard, the results of the MOPC advisory vote, and other relevant information and also provide an advisory vote on the proposed standard. ${ }^{214}$ The standard that emerges from this second advisory vote goes to the regional entity trustees, which recommend that NERC approve the standard, remand it "with comments or instructions," or "determine that there is no need for the standard and terminate any future activity." 15 NERC's Board of Trustees then votes and sends its recommendation to FERC for approval. Figure 1 summarizes this bottomup initiated process.

\section{FIGURE 1:}

The Bottom-up NERC Process for the Development of Regional Reliability Standards

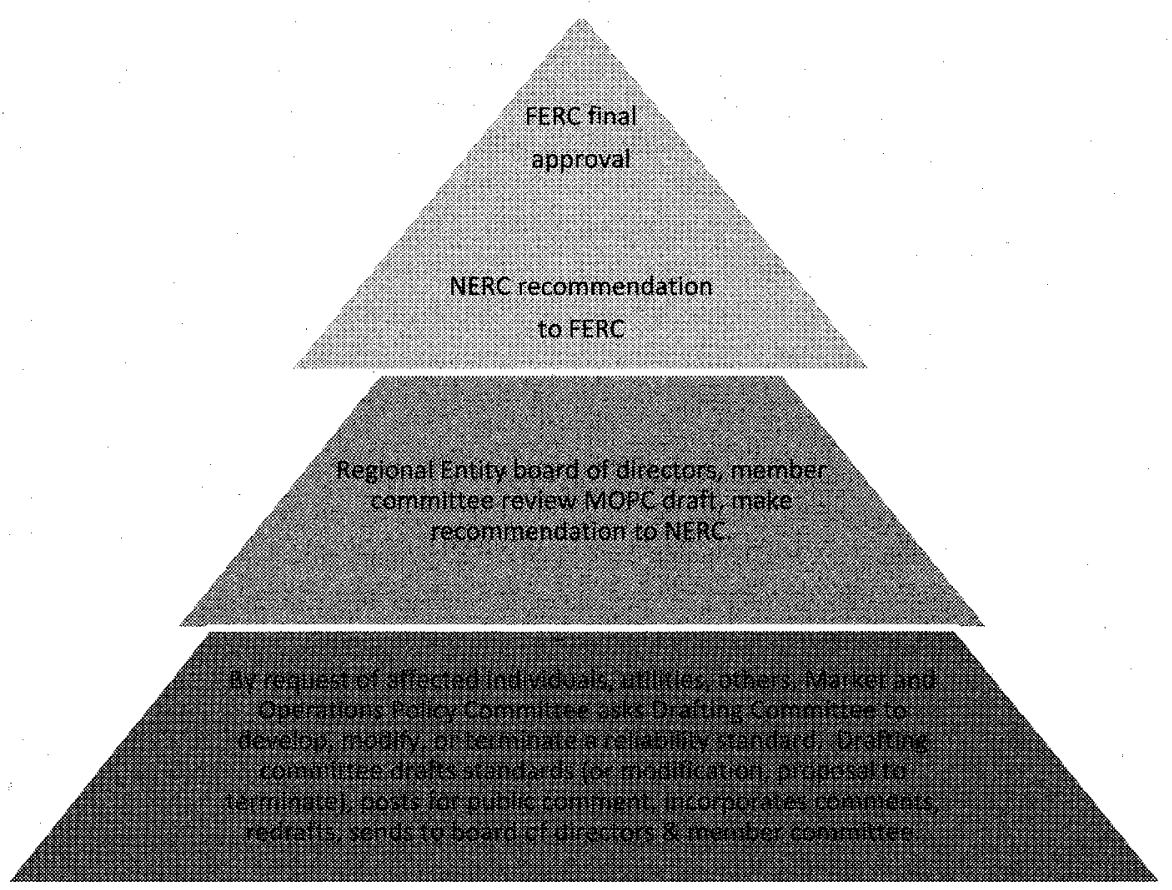

212. Id. at 15 .

213. Id. at 16

214. Id at $16-17$.

215. Id. at 17 . 
NERC's process for drafting national reliability standards is similar. Any interested entity makes a request for a new, modified, or revised standard to NERC's Standards Committee, which appoints a drafting team. ${ }^{216}$ The team follows a similar notice, comment, and redrafting procedure, and the vote on the draft standards goes to NERC's full "Registered Ballot Body," which again consists of a unique public-private mix of utilities, energy marketers, ISOs and RTOs, municipalities that own and operate utilities, state regulators, and others. ${ }^{217}$

Although the standards development process exhibits a bottom-up hierarchy, FERC has recently exerted more top-down authority within NERC's enforcement process, making it clear that it will not simply rubber stamp enforcement decisions. In questioning the adequacy of a number of penalties issued by NERC soon after its approval as the ERO, for example, FERC in a Guidance Order made clear that "[a] monetary penalty must be assessed and structured in such a way that a user, owner or operator of the Bulk-Power System does not consider its imposition as simply an economic choice or a cost of doing business."218

In incorporating these many hybrid elements, NERC as an institution arguably embodies our proposed principles for energy governance. It has used its authority to coordinate what could otherwise be a morass of regulatory overlap. At the extreme, owners of transmission lines each could have followed individual reliability standards, forcing every system user to comply with different mandates; potentially, one generator sending electricity over several transmission lines could have faced three different standards with overlapping and/or divergent requirements. FERC prevented this sort of "pancaking" (layering) in the transmission rate context, but no such prohibition existed for reliability; it emerged organically.

In addition, NERC has prevented a potentially dangerous fragmentation of authority, in which some utilities ignored large system risks and threatened the reliability of an entire portion of the grid. In combining federal oversight with utility-led creation and enforcement of standards, FERC also addresses several holes in authority. States lack jurisdiction over wholesale transmission while the federal government lacks explicit power over certain retail electricity transactions. Even failures in retail distribution lines, however, can affect large portions of the grid, just as flaws in the wholesale transmission system can cut off power for millions of retail users. Congress, in granting FERC authority over all necessary actions for reliability - even those involving retail distribution - has filled

216. N. AM. ElEC. RELIABILITY CORP., supra note 205, at 16, 18.

217. Registered Ballot Body, supra note 197.

218. See generally N. Am. Elec. Reliability CORP., DRafting TEAM Guidelines (2009). available at http:/www.nerc.com/pa/Stand/Resources/Documents/NERCDraftingTeamGuidelines EndorsedbySCApril2009.pdf; see also Rules Concerning Certification of the Electric Reliability Organization; and Procedures for the Establishment, Approval, and Enforcement of Electric Reliability Standards, 18 C.F.R. pt. 39 (2006). 
in potential gaps in authority and coordinated that authority within one institution. At the same time, it has retained the decentralized, private process of standard writing that incorporates key private actors; those most familiar with reliability challenges write the rules.

As with any complex governance system, the many layers of the NERC process can cause problems. FERC's Director of the Office of Electric Reliability, for example, has applauded the "public nature of the reliability standards development process" 219 but has also noted its downfalls. Particularly in the cybersecurity area where new threats often emerge quickly, the bottom-up, grassroots process can impede rapid response. Further, giving private actors such an important role in governance raises the classic concerns of the fox guarding the henhouse, although it also gives rulemaking authority to the entities with the most information in a highly technical field. With these benefits and limitations, the NERC process provides a useful example of a hybrid regulatory structure with regional dimensions creating needed dynamism.

\section{INTEGRATING RENEWABLES ONTO THE GRID: EFFORTS BY REGIONAL TRANSMISSION ORGANIZATIONS}

In addition to a better connected and more reliable transmission grid, almost any model of needed energy transformation includes increasing the number of renewable generation sources on the grid. ${ }^{220}$ These sources require more than the enhanced interconnection potential enabled by the smart grid. Their incorporation requires new transmission lines capable of handling these sources to be built to reach areas with high electricity load, and a reworking of energy markets to handle their intermittency. This Part focuses on the possibility for initiatives by RTOs to meet these needs. It begins by considering the barriers facing renewable integration onto the physical grid and into markets, and then analyzes the hybrid, regional form of RTOs and the extent to which they are overcoming these barriers through governance innovation.

\section{A. Challenges Facing the Integration of Renewables onto the Grid}

Renewables comprise a low percentage of the overall energy mix right now, but the United States has massive untapped potential. For example, the abundant strip of wind resources running up the middle of the country remains largely underutilized, as do areas off the coasts and in

219. N. AM. ELEC. RELIABILITY CORP., supra note 215.

220. See, e.g., LAWRENCE E. JONES, STRATEgIES AND DECISION SUPPORT SySTEMS For INTEgRATING VARIABle ENERgy Resources in CONTROL CENTERS FOR Reliable Grid OPERATIONS 1, 2, available at http://www.eere.energy.gov/wind/pdfs/doe_wind_integration_report.pdf (summarizing studies addressing the integration of wind onto the grid). 
the Great Lakes. ${ }^{221}$ Similarly, the Southwest has extensive solar capacity that is not being used to its full potential. ${ }^{222}$

Once these renewables are connected to the grid, they can serve as a source of cheaper, cleaner energy. For example, in the Midwest Independent System Operator (MISO) transmission system, which has mandates for reducing cost of transmission and enhancing reliability, ${ }^{223}$ transmission operators have attempted to bring as much wind onto the grid as possible because it is generally the cheapest available energy source $;^{224}$ governmental incentive programs that help to reduce the infrastructure costs of installing wind turbines further reduce the price of wind. ${ }^{225}$ This cost minimization thus serves energy law goals of making electricity affordable while assisting the transition to cleaner sources. ${ }^{226}$

Despite their benefits, renewable energy resources have faced interconnection barriers. Existing transmission lines, based around major power plants and population centers, do not reach new sites, and market and regulatory barriers constrain the building of new ones. ${ }^{227}$ Utilities often have little incentive to build new transmission that will encourage competition from other generators, regulatory requirements for open access transmission can only go so far in forcing the construction of new lines, and legitimate interconnection concerns and line constraints often force renewable generators to wait in a transmission queue for months. ${ }^{228}$ In addition, both wind and solar are intermittent; wind speeds and

221. See U.S. DEPT. OF ENERGY, 20\% WIND ENERGY BY 2030 (2008), available at http:/www. 20percentwind.org/20percent_wind_energy_report_revOct08.pdf (describing as-yet unrealized potential); Utility-Scale Land-Based 80-Meter Wind Maps, U.S. DEP'T. OF ENERGY, http://www.wind poweringamerica.gov/wind_maps.asp (last updated Sept. 30, 2013).

222. See Billy Roberts, Concentrating Solar Resource of the United States, NAT'L. RENEWABLE ENERGY LAB. (Oct. 20, 2008), http:/www.nrel.gov/gis/images/map_csp_national_lo-res.jpg.

223. See, e.g., Press Release, Midcontinent Indep. Sys. Operator, Inc., MISO Board Approves 215 New Transmission Projects, (Dec. 8, 2011), available at https:/www.misoenergy.org/About Us/MediaCenter/PressReleases/Pages/MISOBoardApproves215NewTransmissionProjects.aspx (describing "a comprehensive long-term regional plan for the electric grid that will bring more than $\$ 2$ billion in annual benefits for decades to come for energy consumers throughout the Midwest" and that will help the RTO meet its reliability mandates).

224. See, e.g., U.S. ENERGY INFo. AdMIN., LEVELIZEd Cost OF NEW GENERATION ReSOURCES IN THE ANNUAL ENERGY OUTLOOK 2013 (2013), available at http://www.eia.gov/forecasts/ aeo/pdf/electricity_generation.pdf (showing wind projects as costing 89.62011 \$/megawatt hour for new plants entering service in 2018, as compared to conventional coal at $100.12011 \$ /$ megawatt hour); Jeff Kart, Renewables Cheaper than Coal, Michigan Regulators Say, Midwest ENERGY NEws (Feb. 24 , 2012), http://www.midwestenergynews.com/2012/02/24/michigan-regulators-say-renewablescheaper-than-coal/ (noting Michigan Public Service Commission figures, which estimate the average cost of renewables at " $\$ 91.19$ per megawatt hour, compared to $\$ 133$ per megawatt hour for a new coal plant").

225. See 20\% WIND ENERGY BY 2030, supra note 221, at 9.

226. Most states have a requirement that energy prices be "just and reasonable." See, e.g., 220 ILCS 5/9-101 (2013). FERC does the same for wholesale sales, although most wholesale sales are now deregulated and are set by the market rate. 16 U.S.C. $\$ 824 \mathrm{~d}(\mathrm{a})(2012)$. Twenty-nine states also require that a certain percentage of electricity come from renewable sources. See DATABASE OF STATE INCENTIVES FOR RENEWABLES AND EFFICIENCY, supra note 21.

227. See Osofsky \& Wiseman, supra note 8, at 799.

228. See id. at 798 . 
amounts of sunlight vary over time. ${ }^{229}$ This intermittency causes barriers to integrating them into the market, as the aging physical grid often cannot handle large quantities of variability, and traditional pricing systems are not designed to handle these fluctuations. ${ }^{230}$ In addition, certain resources with which renewables are paired do not have the flexibility to rapidly vary the amount of power they provide to accommodate changing wind patterns. ${ }^{231}$

As in the previous two areas of substantive challenges in energy, governance innovation paired with technological changes has the potential to help ameliorate these problems. For example, wind forecasting technology has improved greatly, which allows for innovative regulatory mechanisms to allow greater grid integration. ${ }^{232}$ This innovation also can address the governance challenges inherent to a transmission system that crosses local and state (and sometimes international) lines; demands realtime monitoring as well as long-term planning for electricity sources and needs; and involves generators, line owners, utilities, state agencies, FERC, and regional actors. FERC requirements for uniform interconnection procedures ${ }^{233}$ give wind generators ex ante knowledge of the procedures that will be required to receive approval from utilities or RTOs to connect to transmission lines. Furthermore, innovative RTO proposals to require a variety of grid users to share the costs of building new transmission - which often benefits a variety of generators and consumers, not just wind developers - increases the chances of new lines being built. Section V.C explores how regional transmission organizations, in

229. See Paul Denholm et al., The Role of Energy Storage with Renewable ELECTRICITY GENERATION, NAT'L. RENEWABle ENERGY LAB. (2010), available at http:/www. nrel.gov/docs/fy10osti/47187.pdf ("Both solar photovoltaics (PV) and wind energy have variable and uncertain (sometimes referred to as 'intermittent') output, which are unlike the dispatchable sources used for the majority of electricity generation in the United States.").

230. Probability-Based Software for Grid Optimization, U.S. DEPT. OF ENERGY, http://arpae.energy.gov/?q=arpa-e-projects/probability-based-software-grid-optimization (last visited Oct. 27, 2013) (explaining that "Sandia National Laboratories is working with several commercial and university partners to develop software for market management systems (MMSs) that enable greater use of renewable energy sources throughout the grid" and that the intermittency of solar and wind introduces "complications for MMSs, which have trouble accommodating the multiple sources of price and supply uncertainties associated with bringing these new types of energy into the grid").

231. In Colorado, one industry-funded study suggests that carbon emissions increased following the introduction of wind power as coal plants cycled up and down to accommodate this new influx of variable energy. See BENTEK ENERGY, LLC, HOW LESS BECAME MORE: WIND, POWER AND UNINTENDED CONSEQUENCES IN THE COLORADO ENERGY MARKET (2010), available at http:// westernenergyalliance.org/wp-content/uploads/BENTEK_ExecutiveSummary\%20_HowLessBecame More.pdf. But see Lauren Valentino et al., System-Wide Emissions Implications of Increased Wind Power Penetration, 46 ENVTL. SCl. \& TECH. 4200 (2012) (offering lower emissions numbers). While the use of natural gas as a back-up resource is much more efficient, the barriers described in this paper, from long-term contracts to entrenched infrastructural investments, make it more difficult to rely on the most efficient generation sources as complements to variable ones.

232. Cf. Renewable Energy: Wind Forecast Improvement Project, NAT'L. OCEANIC \& ATMOSPHERIC ADMIN., http://www.esrl.noaa.gov/psd/psd3/wfip/ (last visited Oct. 27, 2013).

233. Interconnection for Wind Energy, Orger No. 661, 111 FERC I 61,353 (2005) (codified at 18 C.F.R. pt. 35). 
particular, have made progress in overcoming governance challenges while expanding transmission to renewable energy farms.

\section{B. Regulatory Innovation Through Hybrid Regional Structures}

As energy firms propose thousands of new renewable energy plants in remote areas, the transmission grid faces unprecedented demands for additional infrastructure construction and market integration. The grid must substantially expand to accommodate a large portion of the proposed generation, and, as discussed in Section V.A, many existing utilities do not have the incentive to build out transmission to new, competing generators. This Section focuses on efforts by multistate RTOs in states with high wind capacity-MISO and the Southwest Power Pool (SPP) - to site transmission lines and integrate renewable energy into the physical grid and market. It explores the extent to which their regulatory innovations address both the substantive and structural issues described in Part II.

\section{Implementing Creative Pricing Schemes and Prioritizing Regional Transmission Build-Out}

RTOs emerged from FERC orders as part of its implementation of the Energy Policy Act of 1992. ${ }^{234}$ As with the other hybrid institutions explored in this Article, RTOs were the result of an ongoing FERC response to a perceived crisis induced by technological and market-based changes, although this crisis was not as discrete or seemingly immediate as blackouts affecting grid reliability or threats of pollution from oil or gas development. ${ }^{235}$ FERC Orders 888 and 889 , followed later by Order 2000 , specifically aimed to address an evolution that was then occurring in electricity markets. ${ }^{236}$ In Order 888 , FERC noted the movement toward independent and affiliated power producers, which often built smaller generation units than did large utilities but needed access to the transmission grid to sell their product. ${ }^{237}$ And following a 1978 act specifically aimed at encouraging the development of numerous small, efficient generators and renewable generation units, transmission access became even more essential to connect consumers with potentially cheaper and cleaner power. ${ }^{238}$ Yet utilities that owned transmission lines created bottlenecks that made it difficult for these competitors to access the grid,

234. See infra notes $241-45$ and accompanying text.

235. Regional Transmission Organizations, Order No. 200, 89 FERC 961,285 (1999) (codified at 18 C.F.R. pt. 35) (in establishing guidelines for the approval of RTOs, noting that "the industry has undergone sweeping restructuring activity" and "[t]rade in bulk power markets has continued to increase significantly," and that as a result of these and other changes, "the Nation's transmission grid is being used heavily and in new ways").

236. Id.; Open-Access Same-Time Information System, Order No. 888, 75 FERC II 61,080 (1996) (codified at 18 C.F.R.pt. 35); Order no. 88975 FERCI 61,087 (1996) (codified at C.F.R. pt. 35).

237. Order No. 888,75 FERC $\$ 61,080$.

238. Id. 
and FERC concluded in Order 888 that open access was necessary to address "the mounting competitive pressures in the industry and rapidly evolving markets." 239

Beginning with Order 888 , FERC fostered the creation of independent system operators, established an electronic information system called the open access same-time information system (OASIS), and later encouraged regional creation of RTOs. ${ }^{240}$ In Order 2000, FERC noted that further "rapid growth" in technologies and the market had occurred since orders 888 and 889.241 The opening of the market had fostered a "rapid growth in dependence on wholesale markets for acquisition of generation resources," and caused similarly "rapid development of new generation resources." "242 But "planning and construction of transmission and transmission-related facilities" was apparently "not keeping up" with the new demands placed on the grid by expanded generation and changing markets, and FERC concluded in Order 2000 that further encouragement of regional transmission entities, some of which had already formed voluntarily, was needed in order to ensure grid reliability and accommodate new generation. ${ }^{243}$

Under Order 2000, RTOs must have independence from market participants, regional scope of operations authority to plan and expand, and an "open architecture policy" that allows for structural modifications. $^{244}$ Their minimum functions include tariff administration and design (the process of obtaining from FERC a regulated rate and approved conditions for the transmission service provided), congestion management, OASIS participation, market monitoring, planning and expansion, and interregional coordination. ${ }^{245}$ As depicted in the following map, there are currently 10 RTOs (some of which include not only U.S. states but also Canadian provinces), which cover about two-thirds of the U.S. population and about one-third of the Canadian population.

239. Id.

240. Promoting Wholesale Competition Through Open Access Non-Discriminatory Transmission Services by Public Utilities; Recovery of Stranded Costs by Public Utilities and Transmitting Utilities, 61 Fed. Reg. 21,540 (May 10, 1996) (codified at 18 C.F.R. pt. 35 and 385); Open Access Same-Time Information System (formerly Real-Time Information Networks) and Standards of Conduct, 61 Fed. Reg. 21,737 (May 10, 1996) (codified at 18 C.F.R. pt. 37); Regional Transmission Organizations, 65 Fed. Reg. 809 (Jan. 6, 2000) (codified at 18 C.F.R. pt. 35); see also Michael H. Dworkin \& Rachel Aslin Goldwasser, Ensuring Consideration of the Public Interest in the Governance and Accountability of Regional Transmission Organizations, 28 ENERGY L.J. 543, 551-54 (2007).

241. Regional Transmission Organizations, Order No. 2000, 89 FERC 161,285 (1999) (codified at 18 C.F.R. pt. 35).

242. Osofsky \& Wiseman, supra note 8 , at 813.

243. Regional Transmission Organizations, Order No. 2000, 89 FERC \ 61,285 (1999).

244. Id.

245. Id.; see Dworkin \& Goldwasser, supra note 240, at 551-54. 
MAP 1:

U.S. Regional Transmission Organizations ${ }^{246}$

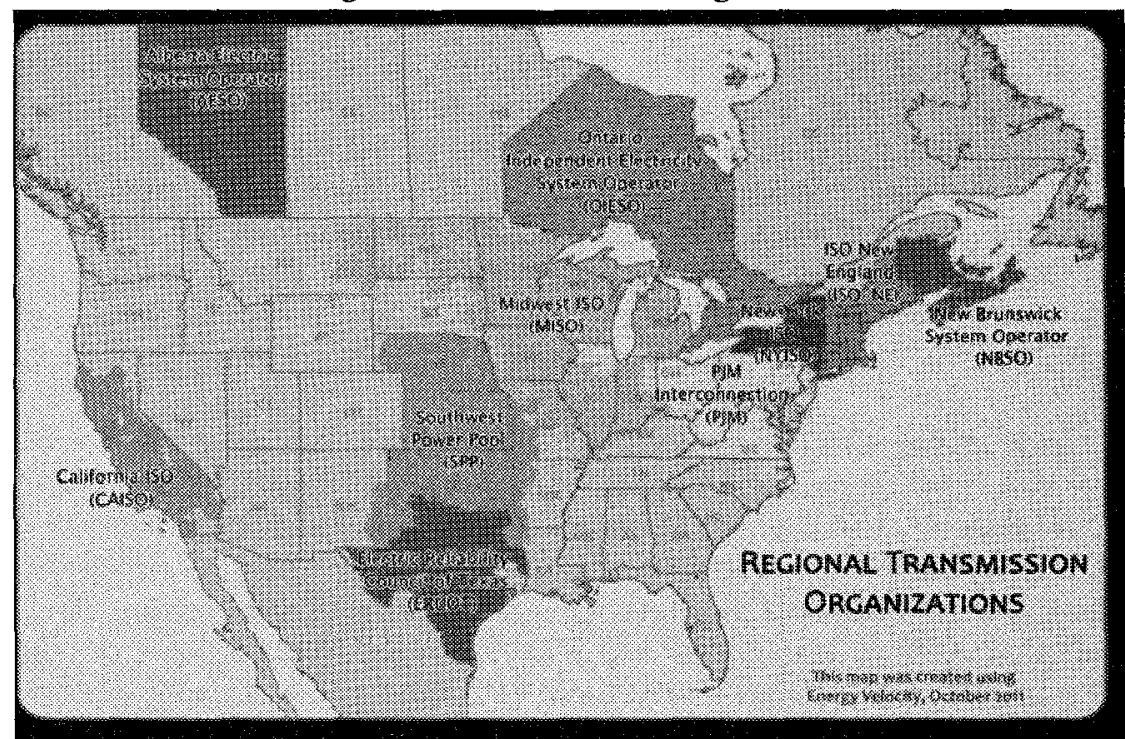

Reproduced from Federal Energy Regulatory Commission Website

The Midwestern RTO, MISO, has been particularly active in addressing renewable challenges as a result of burgeoning interconnection requests from wind generators in the region. In December 2001, MISO became the first RTO approved by FERC. ${ }^{247}$ As of the 2011 ISO/RTO metrics report, it included 33 transmission owners with approximately 57,000 miles of transmission lines and generation owners with 148,456 megawatts of electrical generation. ${ }^{248}$ It covers twelve U.S. states and the Canadian province of Manitoba, and in 2010, cleared more than $\$ 25.7$ billion in energy transactions. ${ }^{249}$ MISO includes states that have among the highest wind capacity in the United States and was among the first RTOs to proactively include wind in its transmission planning process, beginning in 2003, through its Midwest ISO Transmission Expansion Plan and continuing in all of its transmission planning since..$^{250}$

As Alexandra Klass and Elizabeth Wilson have discussed in recent scholarship, MISO's Multi-Value Project pricing approach has the poten-

246. Regional Transmission Organization (RTO) / Independent System Operators (ISO), FED. ENERGY REGULATORY COMM'N, http://www.ferc.gov/industries/electric/indus-act/rto.asp (last updated Oct. 17, 2013).

247. CAL, INDEP. SYS. OPERATOR CORP. ET AL., 2011 ISO/RTO METRICS REPORT 145 (2011), available at https:/www.misoenergy.org/Library/Repository/Tariff/FERC\%20Filings/2011-08-31\% 20Docket\%20No.\%20AD10-5-000.pdf.

248. Id.

249. The MISO states include Illinois, Indiana, Iowa, Michigan, Minnesota, North Dakota, South Dakota, Wisconsin, and parts of Kentucky, Missouri, Montana, and Ohio. Electric Power Markets: Midwest (MISO), FED. ENERGY REGULATORY COMM'N, http://www.ferc.gov/market-oversight/mktelectric/midwest.asp (last updated Oct. 11, 2013).

250. CAL. INDEP. SYS. OPERATOR CORP. ET AL., supra note 247, at 158, 160. 
tial to help overcome cost allocation barriers to new transmission lines that will help bring renewable energy onto the grid and assist its states in meeting their renewable energy goals. ${ }^{251}$ The MVP model introduces a new pricing scheme in which the amount of load on the new lines will affect the price that an area within the region pays. 252 Projects that meet certain requirements, such as participating in MISO's transmission expansion planning process, "provid[ing] multiple economic benefits," and addressing regional reliability standards, may participate. ${ }^{253}$ The MVP approach has thus far survived challenges by those who oppose it - the Seventh Circuit upheld the plan in June 2013-and it represents a promising effort to integrate renewables more effectively into the physical grid. ${ }^{254}$

Indeed, MISO's approaches to transmission governance have correlated with tangible gains on needed energy transformation. For example, a 2007 study by the ISO/RTO council indicated that RTOs help to implement renewable portfolio standards by tracking generation, and that ISOs and RTOs support markets' integration of renewable resources. It noted that at that time, ISOs and RTOs hosted $79 \%$ of installed wind generation, "which is well above their $44 \%$ share of wind energy potential and $53 \%$ share of total North American electricity demand."25s While this disproportionate share is likely due in part to RTOs' fortuitous concentration in the Midwest, which has abundant wind, RTOs likely have directly supported enhanced investment in renewable generation, at least in part.

In addition to this work on transmission, MISO's new resource designation of Dispatchable Intermittent Resources (DIRs) is allowing wind energy to participate fully in the real-time markets rather than just the day ahead ones for the first time. ${ }^{256}$ This innovative approach to bringing

251. Alexandra B. Klass \& Elizabeth J. Wilson, Interstate Transmission Challenges for Renewable Energy: A Federalism Mismatch, 65 VAND. L. REV. 1801, 1870-71 (2012).

252. Id.

253. Id. at $\mathbf{1 8 5 2 .}$

254. See Ill. Commerce Comm'n v. Fed. Energy Regulatory Comm'n, 721 F.3d 764 (7th Cir. 2013). For a discussion of how the MISO plan that was upheld was structured somewhat differently than a regional plan by another RTO that the Seventh Circuit struck down, see Klass \& Wilson, supra note 251 , at 1854 .

255. ISO/RTO COUNCIL, INCREASING RENEWABLE RESOURCES: HOW ISOS AND RTOS ARE HELPING MEET THIS PUBLIC POLICY OBJECTIVE ES-1-2 (2007), available at http://www.isorto.org/ atf/cf/\%7B5B4E85C6-7EAC-40A0-8DC3-003829518EBD\%7D/IRC_RENEWABLES_REPORT 101607_FINAL.pdf.

256. Press Release, MISO, Miso Furthers Wind Integration into Market (June 1, 2011), available at https://www.misoenergy.org/AboutUs/MediaCenter/PressReleases/Pages/MISOFurthersIntegrationof WindResources.aspx; see also generally MISO, DISPATCHABLE INTERMITTENT RESOURCE

IMPLEMENTATION GUIDE (2011), available at https:/www.misoenergy.org/Library/Repository/Report/ DIR\%20Implementation\%20Guide.pdf. For a discussion of integrating intermittent renewable resources into energy markets, see Walter R. Hall II, et al., American Bar Association Energy and Resources Committees, Restructuring of the Electric Industry, 2008 ABA ENVTL. ENERGY \& RESOURCES L.: YEAR IN REV. 296; Audun Botterud et al., Wind Power Forecasting in U.S. Electricity Markets, 23 ELECTRICITY J. 71 (2010); J.C. Smith et al., Impact of Variable Renewable Energy on US Electricity 
wind more fully into the market, using improved wind prediction technology, has the potential to limit wind curtailment and pave the way for even more integration in the future. For example, MISO is not yet allowing DIRs to supply operating reserves, but has expressed its openness to doing so in the future after this experiment. ${ }^{257}$ While controversy remains over some of the particulars, MISO's pricing efforts, like its transmission activities, represent important steps forward in integrating renewable energy into the market dimensions of the grid.

Other RTOs have begun to make similar progress in expanding transmission to renewables. The Southwest Power Pool (SPP), an RTO that covers 255,000 square miles in Oklahoma, Kansas, the Texas Panhandle, and parts of New Mexico, Missouri, Arkansas, and Louisiana, ${ }^{258}$ also operates within a very windy region. Although it has not been as aggressive as MISO in expanding transmission for wind power, it has taken important planning steps. In 2004 alone, SPP had 37 interconnection requests from generators in process, including 26 requests from wind generators. ${ }^{259}$

To address anticipated future interconnection requests and a number of other impending transmission challenges, SPP conducts both local and regional planning to operate and continuously update its grid effectively. For example, SPP initiated a process to plan for a "cohesive group of economic transmission upgrades" benefitting the region and to determine how to allocate the costs of upgrades regionally. ${ }^{260}$ Two additional local area planning processes created a plan to build an "extra high voltage transmission backbone" across the region and to annually review "transmission expansion needs over a 10-year horizon" to determine how grid reliability would be maintained. ${ }^{261}$

In 2009, SPP announced that it would pull together these transmission planning processes into one process called the Integrated Transmission Plan, which addresses the need to maintain grid reliability and allow for economic development through the interconnection of new generation, including wind. ${ }^{262}$ When this plan is implemented, it will "result in a

\footnotetext{
Markets (draft manuscript on file with authors); Li Zhanget et al., Generation and Demand Management Improvement with Increased Variable Generation: $A$ Midwest ISO Perspective, IEEE (2011).

257. See Order Conditionally Accepting in Part and Rejecting in Part Tariff Filing and Requiring Compliance Filings, 134 FERC $\mathbb{~ I ~ 6 1 , 1 4 1 ~ ( F e b . ~ 2 8 , ~ 2 0 1 1 ) ; ~ O r d e r ~ D e n y i n g ~ R e h e a r i n g , ~} 136$ FERC $\mathbb{I}$ 61,100 (Aug. 12, 2011).

258. ISO/RTO Planning COMm., ISO/RTO Electric System Planning: Current Practices, Expansion Plans, and Planning Issues 156 (2006), available at http://www.ercot. com/news/presentations/2006/IRC_PC_Planning_Report_Final_02_06_06.pdf.

259. Id. at 159.

260. Sw. Power Pool, Integrated Transmission Planning Process Document 6 (2009), available at $\mathrm{http}: / / \mathrm{www} . \mathbf{s p p} .0 \mathrm{rg} /$ publications/itp_process_final_20091029.pdf.

261. Id.

262. Id. at 3, 6 (describing the purpose, noting that study assumptions will include "wind profiles," and noting that the new ITP process must capture the goals of each planning process integrated into the larger process, including the goal of "utilization of the area's large renewable resources").
} 
list of transmission expansion projects and completion dates."263 The RTO has already completed a cost allocation strategy to distribute more costs of grid upgrades for wind throughout the region. ${ }^{264}$ It has also joined a larger regional group, which covers the entire grid that services the eastern United States (the Eastern Interconnection Planning Collaborative), to "focus on interconnection-wide expansion plans" for wind. ${ }^{265}$

Beyond planning for transmission expansions, SPP must accommodate interconnection requests that it already has received. It initially did this by evaluating specific interconnection requests from generators; when SPP received a large number of wind generation requests, however, it began aggregating them within "cluster studies."266 These showed that new extra high voltage facilities (EHV) would be required and that some of these upgrades were not included within the planned transmission backbone. ${ }^{267}$ SPP therefore formed a separate technical planning process, which creates a model with various assumptions about the amount and type of new generation that will come online within the region (including high wind scenarios, for example), economic needs, and reliability.

While no entity can fully address the challenge of rapidly growing renewable generation and interconnection requests, the structure and functions of RTOs have improved renewable access. As the RTO/ISO planning committee noted in 2006: "The ISOs/RTOs have been successful in creating nondiscriminatory, open, and transparent electric system planning and expansion planning processes that provide an opportunity for all stakeholders to participate. The ISO/RTO planning processes remain dynamic and are still evolving."268

\section{Forging Horizontal and Vertical Connections}

RTOs, by bringing together utilities, state utility commissioners, and disinterested experts in the governance of transmission planning and operation, forge needed interactions among the many parties affected by the grid. Professor Michael Dworkin provides a useful framework through which we might structurally characterize RTOs, alternatively understanding them as: (1) agents of the Federal Energy Regulatory Commission; (2) monopolies, private entities that need regulation like other monopolies in the energy market; (3) hybrid, quasi-governmental organizations, (4) a commodities trading market; (5) agents of transmis-

263. Id. at 4 .

264. Sw. POWER POOL, WIND INTEGRATION 1 (2010), available at http:/www.spp.org/ publications/SPP_Wind_Integration_QA.pdf.

265. Id. at 2 .

266. Sw. POWER POOL, supra note 260 , at 6 ; for generation request data, see ISO/RTO PLANNING COMM., supra note 258, at 159.

267. Sw. POWER POOL, supra note 260, at 6.

268. ISO/RTO PLANNING COMM., supra note 258, at 10. 
sion owners in a region; or (6) a regional planning process. He explains that each of these characterizations has validity, but none fully describes them. ${ }^{269}$

These various views of RTOs reinforce the way in which they crosscut the levels of government and integrate public and private actors, which are crucial components of the governance challenges described in Section I.A. RTOs play and have the potential to play important roles in helping to overcome some of the federalism barriers to effective grid transformation generally and integration of renewables in particular because of their hybridity. While they are certainly not perfect, and there is much analysis of the benefits and limitations of their form and some of their actions, ${ }^{270}$ RTOs help to create a bridge both vertically between the federal and state governments and horizontally among their member states. This bridging is an important step towards full authority over the planning of wires that often cross multiple jurisdictional lines and to avoid overlap and fragmentation in this planning process. RTOs receive frequent orders from FERC, including, for example, recent directives for interconnecting wind farms. ${ }^{271}$ When RTOs propose changes to their tariffs in order to implement these orders, they engage in frequent backand-forth communications with FERC. ${ }^{272}$ Member states, in turn, cooperate both through RTOs and associated institutions, such as the Organization of MISO states, to support or oppose the RTOs' proposed policy changes in response to FERC orders.

MISO's DIR approach, in particular, which integrates wind into the real-time electricity market run by the RTO, has been shaped by an interaction among MISO, FERC, and entities challenging MISO's approach. MISO formulated its particular approach under section 205 of the Federal Power Act. Some regulated entities and groups representing them then filed a challenge to aspects of the approach. FERC accepted and rejected parts of the approach and then denied rehearing. ${ }^{273}$ MISO's hybrid, regional role in that process - as both a regulated and regulating entity addressing regional concerns around wind integration-helped to provide a new model for market integration.

To implement expanded transmission for anticipated future generation, SPP has relied on similar institutional mechanisms that integrate ac-

269. Dworkin \& Goldwasser, supra note 240, at 554-57.

270. For a summary of this debate, see $i d$. at 578-91.

271. For a discussion of MISO's efforts to integrate wind, see Order Conditionally Accepting in Part and Rejecting in Part Tariff Filing and Requiring Compliance Filings, supra note 257; Order Denying Rehearing, supra note 257.

272. For an example of these dynamics, see Order Conditionally Accepting in Part and Rejecting in Part Tariff Filing and Requiring Compliance Filings, supra note 257; Order Denying Rehearing, supra note 257.

273. For a discussion of the orders establishing RTOs, see supra notes $242-46$ and accompanying text. For a discussion of the process by which MISO established the DIR and challenges were made to it, see Order Conditionally Accepting in Part and Rejecting in Part Tariff Filing and Requiring Compliance Filings, supra note 257; Order Denying Rehearing, supra note 257. 
tors from multiple levels. Through its "local area (sub-regional) planning process" to address existing interconnection requests, for example, it meets quarterly with stakeholders from SPP's geographic "subregions" to discuss local needs and to hear any requests for high-priority transmission projects. ${ }^{274}$ This process helps facilitate agreement around transmission and communication about concerns.

Both the underlying RTO structure and RTOs' efforts to foster transmission and market integration have begun to effectively address gaps and overlap in authority, including questions of where each actor falls within the decision making hierarchy for transmission planning and the extent to which these actors cooperate and conflict. The MISO processes around transmission build-out and market integration create structured bidirectional hierarchy, for example, and the MVP and DIR approaches, discussed above, allow for iterative interactions among MISO and FERC, MISO and stakeholders, and FERC and stakeholders. These interactions sometimes involve conflict, even formal challenges raised before FERC and federal courts. But the combination of these challenges with formal approval processes that allow for stakeholder input under FERC and MISO have helped connect and coordinate the many actors involved in expanding transmission to renewables. These processes, through both bridging authority and locating it at a regional level, allow for needed progress.

\section{Including Public and Private Actors in Multidirectional Planning Processes}

In addition to connecting several governance levels, RTOs also have effectively integrated public and private stakeholders. The processes for including these stakeholders are both bottom-up and top-down, thus balancing grassroots input with public review; this may help to avoid capture of the process by any one actor. SPP, for example, which had to decide on essential yet disparate plans for both existing grid interconnection requests and future transmission needs, developed an inclusive Balanced Portfolio planning process. ${ }^{275}$ In 2009, the SPP Board of Directors formed a new stakeholder planning group - the "Synergistic Planning Project Team" (SPPT), consisting of electric cooperatives, state electricity regulators, utilities, capital groups, and SPP staff. ${ }^{276}$ This group proposed a plan to coordinate various local and regional planning processes, and the plan has since been adopted by the SPP, which models needs for likely future generation. ${ }^{277}$ Under this plan, a number of SPP stakeholder groups, such as those dealing with the allocation of transmission costs across the region and environmental issues, propose the scenarios to be

274. SW. POWER POOL, supra note 260 , at 7.

275. Id. at 6.

276. Id. at 5 .

277. Id. 
used in the model, and stakeholders then approve them. ${ }^{278}$ An SPP working group then finalizes development of the model and runs it, proposing transmission solutions based on model results. ${ }^{279}$ The Board of Directors ultimately approves the solutions generated by the Integrated Planning Process following another stakeholder review. ${ }^{280}$ Through the process, stakeholders reach a consensus on how to ensure that benefits of new transmission projects would be equally allocated throughout the region and how costs would be transferred to match benefits, ${ }^{281}$ and the Board of Directors approves the resulting plan.

Together, MISO and SPP model the dynamic role that hybrid, regional entities are playing in addressing grid-related federalism challenges. They serve as an interface between national and state regulatory entities and a range of important private and quasi-private actors, and use their role to attempt to overcome barriers to progress at state and federal scales.

As with the previous two sets of examples, MISO and SPP efforts are not unmitigated successes. Most fundamentally, their experiments are young, and it is still unclear whether their transmission and market efforts will actually achieve their goals or, in some instances, even survive judicial review. Not all stakeholders buy in to their approaches, as evidenced, for example, by challenges to the DIR made through the FERC regulatory process. ${ }^{282}$ Moreover, as organizations with voluntary membership, RTOs cannot compel stakeholders to become members and participate. Even with these limitations, however, their innovative efforts to make progress through a hybrid, inclusive structure at regional effort represent an important example of possible ways forward.

\section{BENEFITS AND LIMITATIONS OF INSTITUTIONAL HYBRIDITY}

The U.S. energy institutions described in the previous Part have made admirable progress in the face of significant substantive and structural barriers. Facing the difficult tasks of updating an entire grid for reliability and clean energy while reducing risks in the extraction of fuelsthe lifeblood of the electricity generation system - these institutions are grappling with the need to coordinate actors from all levels of governance, and, increasingly, thousands of stakeholders. Their practical efforts suggest ways in which regional, hybrid institutions may play an important role in future energy governance challenges.

In order to conduct a normative assessment of whether these innovations should be viewed as successful, this Part explores the broader

278. Id. at 9 .

279. See id. at 10-14, 16 (describing the process testing models in twenty-year, ten-year and Near Term Assessments).

280. See id. at 19.

281. See id. at 6.

282. See supra notes $262-63,279$. 
patterns emerging from these examples drawn from diverse and at times divergent areas of energy law. It assesses the benefits and limitations of these types of governance innovations as a tool for energy transformation, with a focus on both policy and governance achievements. It begins by considering the difficulties of defining success and then turns to an examination of their substantive and structural roles.

\section{A. Difficulties of Defining "Success"}

To evaluate whether hybrid regional entities may successfully address future substantive energy challenges while overcoming governance barriers, one must of course have a definition of success. But the dual nature of our inquiry makes this definition more difficult to establish: we are interested both in whether these institutions are making substantive progress in addressing the need for energy transition and whether their governance approach in achieving this progress is a constructive one. The latter part of our inquiry also potentially raises long-standing philosophical debates about process-based versus ends-based evaluation of success. While an involved exposition of deontology versus teleology, or how to conduct utilitarian measurement, is beyond the scope of this paper, there is arguably value in having a better energy governance process even if the outcomes remain the same.

Given this framing complexity, our assessment in this Part takes two primary steps. First, we engage in a substantive inquiry that asks whether these institutions have made progress in addressing the three sets of challenges we have identified. More simply put, have they helped (1) make unconventional fuel extraction less risky, (2) improve grid reliability in the context of a transition to a smart grid, and (3) integrate renewables onto the physical grid and into the energy market?

This measure of success is designed to address the ends-based concerns of whether these types of governance innovations appear to be helpful to achieving energy transition. Our assessment approach involves qualitative case studies rather than quantitative empirical methods. We acknowledge the value of future quantitative empirical work in this area, but the goal of this Article is to provide a more nuanced exposition of several examples than quantitative analysis generally provides in order to understand how and why governance innovation might translate into substantive success in the energy system.

In addition to focusing on specific ends-based substantive goals of energy transformation, this Part also considers a second measure of success: whether these governance innovations actually embody the three principles for more effective governance introduced in Dynamic Energy Federalism. As explored in depth in that piece, we have core concerns with the energy system's complexity and with its silos. We have proposed that more dynamic, holistic treatment of interlinked federalism and governance relationships in the energy system would benefit the system as a whole and specifically, that a dynamic energy federalism model 
must draw together actors from all governance levels affected by or involved in energy changes, better integrate these actors, and allow for enhanced levels of private entity involvement accompanied by stakeholder participation and other mechanisms to lower the risk of inefficient capture.

In arguing for this governance system, we acknowledge the difficulties of achieving foundational changes to underlying statutes and regulatory approaches, particularly in the current political climate. These hybrid, regional structures have promise in part because they may have the capacity to produce more effective governance without major reform. We therefore also conduct a structural assessment of success based on our case examples in order to determine whether these institutional innovations can fill gaps in authority, reduce fragmentation, and integrate key public and private stakeholders without capture.

\section{B. Substantive Assessment}

Substantively, as described in the case examples of Parts III through $\mathrm{V}$, regional hybrid institutions have made some meaningful progress toward addressing all three modern energy challenges that are the focus of this Article. In the process, they appear in some instances to have made-and to have the potential to make-energy cheaper, fairer, and cleaner. None of these institutions has achieved unmitigated success, though, and much room for progress remains. In each example, substantial structural barriers have sometimes limited their achievements and may continue to do so. Moreover, the newness of some of these regulatory experiments means that their effectiveness has not been fully tested.

In the area of controlling the risks of unconventional fuel development, RCACs identify the many risks of oil spills through a relatively comprehensive approach, including both monitoring and the proposal of substantive mechanisms to prevent and respond to risk; this, in turn, may ensure better environmental protection. By drawing in diverse stakeholders, they also prevent an assessment of risks through one lens, which could miss the powerful effects of spills on certain populationsparticularly on communities that rely on ocean resources for their subsistence. This will potentially reduce unfair burdens on disadvantaged groups in future spills, and it also enhances the inclusiveness of the process. Further, these councils do not appear to have imposed high costs on energy development, although perhaps their focus on "recommendations" and monitoring, as opposed to extensive substantive action, places too high of a premium on development over environmental protection.

It also remains unclear how successfully this model could be brought into the context of deepwater drilling. RCACs have not yet been established in the Gulf region despite the many calls for such an approach in the aftermath of the BP Deepwater Horizon oil spill. If they were, their structure and goals would likely need to be much more complex than the current RCACs in the Alaskan context; the Gulf and its 
communities are far less environmentally pristine and far more populated than the region where the Exxon Valdez spill took place. The steps that these two RCACs have been able to take and the assessments of their progress thus far suggest, however, that they have the ability to complement other regulatory processes and reduce the risks of oil spills. $^{283}$

In unconventional onshore natural gas extraction, hybrid regional entities have been more involved in attempting to directly regulate multiple aspects of drilling and fracturing. As introduced in Part III, the Delaware River Basin Commission-composed of state representatives and one federal representative-proposed to control the nonpoint source pollution from well pads, require baseline testing of waters for pollutants prior to drilling and fracturing, extensively regulate water withdrawals, and approve the means and location of disposing of drilling and fracturing waste, for example; these measures would have provided relatively comprehensive and direct control of risks. ${ }^{284}$

Despite its progress in navigating the complex governance interactions that occur along horizontal and vertical axes, the institution's regulations may ultimately fail. The DRBC's own member states have engaged in increasingly conflictual, noncooperative relationships with it, arguing that the regulations inadequately protect against environmental risks. ${ }^{285}$ Furthermore, the DRBC regulations, if finalized, would cover only water quantity and quality risks. Fragmented and divergent state and local regulations would have to fill in the remaining problem areas, and, if recent trends continue, ${ }^{286}$ they would not be wholly successful in this task.

Moving from governance of the risky extraction of fuel used in power plants to electricity generation itself, NERC, as a hyperregional institution (a collective of regional entities, which are collectives of states) and a hybrid with numerous public and private actors, appears to have achieved reasonable success in enhancing grid reliability despite widespread computerizing of the grid and structures attached to the grid. FERC has approved new cybersecurity standards proposed by NERC, ${ }^{287}$ and a number of utilities have taken important new cybersecurity measures. ${ }^{288}$

283. See supra Part III.

284. See Revised Draft of Natural Gas Development Regulations, supra note 78, at 47-84.

285. See, e.g., supra notes 133-35.

286. See generally NATHAN RICHARDSON ET AL., THE STATE OF STATE SHalE Gas REGULATION (2013), available at http://www.rff.org/rff/documents/RFF-Rpt-StateofStateRegs_ Report.pdf (showing substantial differences among states' regulations as well states that lack regulations for certain areas of well development, and describing recent regulatory changes, which are not uniform).

287. See, e.g., Version 4 Critical Infrastructure Protection Reliability Standards, 139 FERC $\mathbb{f}$ 61,058 (Apr. 19, 2012) (to be codified at 18 C.F.R. pt. 40).

288. See generally MILES KEOGH \& CHRISTINA CODY, CYBERSECURITY FOR STATE REGULATORS 5 (2012), available at http://energy.gov/sites/prod/files/NARUC\%20Cybersecurity \%20for\%20State\%20Regulators\%20Primer\%20-\%20June\%202012.pdf (suggesting states are "im- 
But as in the example of the risks associated with unconventional fuels, significant concerns remain. According to some consultants, many utilities still are at risk of computing-related interruptions, ${ }^{289}$ and the implementation of cyber-security measures will be costly; ${ }^{290}$ it is not entirely clear whether the costs exceed the benefits of avoiding disruptions from computerized attacks or other interruptions. Furthermore, some critics have suggested that small utilities have not been diligent in implementing cybersecurity measures; ${ }^{291}$ in some regions, this could mean that customers that already face disadvantages due to limited access to diverse and cheap generation could experience additional reliability problems in the event of computer failures. Overall, NERC's success in preventing most massive blackouts despite an aging infrastructure and a multiplicity of new demands on the grid speaks to its general success, ${ }^{292}$ but additional implementation and testing over time is needed to assess the ultimate success of its efforts to adapt reliability approaches to changing technology.

RTOs' efforts to integrate renewables onto the grid have thus far been the most clearly successful of our examples, but they are at early stages of implementation, making their long-term achievements still unclear. For example, MISO's transmission planning process that prioritizes projects with MVP designation has tremendous promise and is functioning well thus far. As Alex Klass and Elizabeth Wilson observe:

FERC approved the MVP model in December 2010 and the MISO

Board approved the projects in December 2011. The pricing model allows regionally oriented projects to have their costs allocated across the MISO region on a "postage-stamp" (load-ratio share) basis. To be considered for MVP status, a proposed project either must: (1) be developed through MISO's transmission expansion planning process for the purpose of meeting various energy policy laws or mandates; (2) provide multiple economic benefits to multi-

plementing energy assurance plans across the country that help respond to vulnerabilities, as well as preventing and protecting against threats").

289. See Cyber Security Measures a Must for All Utilities, Expert Tells Seattle Gathering, PUBLIC POWER WEEKLY (June 25, 2012), http:/www.naylornetwork.com/app-ppw/articles/index-v2. asp?aid=180746\&issueID=23334 ("Many public power utilities run enterprise and operations programs on a single flat network, he said. Those computer systems should be run on separate networks-one for enterprise (billing, engineering, desktop users) and one for operations (substation, SCADA, metering, distribution, generation and transmission).").

290. See generally KEOGH \& CODY, supra note 288, at 12-13 (noting that "in the face of shrinking budgets, fluctuating workforce and the absence of comprehensive legislation, regulators need a dynamic strategy to strike the right balance of security and resources" and that "regulators must keep the cost of electricity affordable for customers while asking utilities to spend more on cybersecurity in the face of increasing media attention on stories of cybersecurity threats").

291. See Cyber Security Measures a Must for All Utilities, Expert Tells Seattle Gathering, supra note 289 (suggesting that small utilities may view the cybersecurity standards as being important only for large utilities).

292. Cf. N. AM. ElEC. RELIABILITY CORP., 2012 ANNUAA REPORT 13 (2013), available at http:// www.nerc.com/files/NERC\%202012\%20Annual\%20Report\%20\%28MAR13\%29.pdf (concluding in a self-assessment that "[r]eliability of the bulk power system remains adequate with little change in trends between 2008 and 2011 " but noting some significant reliability issues). 
ple regions, while the project's total economic benefits are greater than the total economic costs; or (3) address an issue related to a regional reliability standard, while the project's total economic benefits are greater than the total economic costs. In creating a new cost allocation methodology for MVP projects, "Midwest ISO projects that the MVP starter projects developed within the first five to ten years following approval of the proposed MVP cost allocation methodology will generate between $\$ 400$ million to $\$ 1.3$ billion in aggregate annual adjusted production cost savings, spread almost evenly across all Midwest ISO Planning Regions. ${ }^{293}$

This process, while efficient, has addressed important environmental values in its expansion of transmission access for renewables, and also has focused directly on fairness in its requirement that the projects provide benefits to "multiple regions." 294 Further, the process to implement the MVP involved multiple public meetings with options for stakeholder input. ${ }^{295}$ Until these lines actually are built and in operation, however, we cannot know with certainty how much progress this program will make in bringing renewable sources onto the grid.

Similarly, MISO has successfully implemented its DIR approach, after revising it somewhat over the course of the FERC regulatory process. As a result, wind producers have begun to participate in the real-time energy market for the first time. Because this implementation has occurred over the last several months, though, it is still too early to know how effectively this market mechanism will reduce wind curtailment over time (instances when wind producers cannot put all of their available wind onto the grid). As of now, the DIR program's main accomplishment has been to create fuller market participation, an important gain.

These rather mixed substantive results provide a window into both the benefits and limitations of these kinds of governance experiments as a tool in energy transition. On the one hand, these hybrid, regional institutions have made some progress in addressing substantive challenges. They each have developed new regulatory standards and approaches in rapidly-evolving areas of the energy system; such efforts are needed to help the system be responsive to change. On the other hand, these examples contain many instances of groups of dissatisfied stakeholders and of proposals that never solidified. Considering these concerns and preliminary progress, we are guardedly optimistic that this governance innovation has the capacity to translate into needed regulatory innovation.

293. Klass \& Wilson, supra note 251 , at $1851-52$.

294. Id. at 1852.

295. Candidate MVP Portfolio Study, MISO, https:/www.midwestiso.org/Planning/Pages/ MVPAnalysis.aspx (last visited Oct. 28, 2013) ("High-level study updates were provided at the Planning Advisory Committee (PAC), Planning Subcommittee (PS) and the Subregional Planning Meetings (SPMs). Candidate MVP Technical Study Task Force (TSTF) meetings were also held throughout the study on at least a monthly basis. Finally, weekly updates were sent to stakeholders via the Planning Advisory Committee (PAC) mailing list."). 


\section{Structural Assessment}

Our structural assessment parallels the substantive one and is closely intertwined with it. All of the institutions described in this Article represent significant steps towards our recommended governance principles, and these innovations appear to be important contributors to the substantive gains that they have made thus far. None of these institutions, however, has completely solved the governance problems we identified in Dynamic Energy Federalism. Gaps in authority and fragmented authority remain, and often serve as important barriers to these institutions achieving their regulatory goals. These institutions' integration of private actors has also had naysayers from both directions, including those who think that some important private interests have not been wellenough incorporated and those that think private interests have been too well incorporated. Despite these limitations, and at times perhaps because of them, these institutions serve as important examples of the types of governance innovations that could play a central role in supporting energy transitions toward less risky fuel extraction, grid reliability, and more renewables. This Section uses the three governance principles to explore these issues.

First, all of these hybrid arrangements establish significant authority at a regional level, which helps to address some of the gaps in authority in the relevant substantive areas. In the hydraulic fracturing and oil spills context, this regional focus allows RCACs and groups operating under interstate compacts, such as the DRBC, to address geographically intertwined concerns with key stakeholders involved. The NERC regional entities similarly convene regional interests and conduct enforcement at that level; because one grid outage can affect an entire region, and the grid is increasingly interconnected as a result of new technologies, regionalism serves as a critical interstitial space. Likewise, regional-level authority allows the RTOs to convene sometimes conflicting stakeholders and bridge state and national-level authority gaps around allocating cost for new transmission lines and integrating more intermittent sources into price structures.

As noted in the above analysis, this gap-filling is not comprehensive. These regional-level institutions do not supplant the partial authority of the relevant federal, state, and local governments; they are limited to using their powers to create additional, umbrella-type authority at a regional level that can create needed convergence. As a consequence of this limited authority, these institutions face many checks and hurdles as they attempt to achieve their goals. This partial gap-filling suggests that regional hybrid approaches can help ameliorate the problem of inadequate authority without requiring major legal or institutional reform, but cannot fully solve it.

Second, with respect to the problem of simultaneous overlap and fragmentation, each of these institutions integrates multiple governance 
levels into their processes with possibilities for bottom-up input. All of these structures help to resolve questions of hierarchy through their inclusive processes. For example, both the DRBC and RCAC involve high levels of stakeholder participation and include governmental and nongovernmental entities constituted at different scales within that stakeholder group. Similarly, NERC and RTOs conduct processes that allow both individual end users and utilities significant opportunities for input. This type of overlap can be highly beneficial when well-coordinated, as Jody Freeman and Jim Rossi have observed. It may reduce the costs of decision making by, for example, "streamlining redundant functions" like information gathering. ${ }^{296}$ Further, it may lower the costs to stakeholders of participating in the regulatory process and encourage the pooling of agency expertise, among other benefits. ${ }^{297}$

These institutions and their fit within broader regulatory structures also provide opportunities for iterative conflict and cooperation. After states were upset with the DRBC process, for example, it began holding more meetings to try to achieve a compromise. ${ }^{298}$ The RCACs similarly try to find common ground among disparate groups and address areas where disagreement persists. When FERC reviews and criticizes regulatory decisions by NERC and RTOs or stakeholders challenge them, those entities respond, often with modifications.

As with the first principle of progress toward substantive energy goals, these institutions' governance successes are only partial. By bringing key stakeholders together, they decrease overlap and fragmentation and provide opportunities for coordinated action. Because significant fragmented authority remains at multiple levels of government, however, they cannot achieve full integration. From a normative perspective, this state of affairs may at times be positive. After all, the U.S. system of government, with its separation of power, checks and balances, and federalist structure, is founded on the idea that too much consolidation of authority can lead to problematic institutions and outcomes. Along these lines, some of the dissent in the examples may lead to better policies; if for example, the DRBC's standards do not provide enough environmental protection, the state opposition may help to prevent the emergence of a regulatory scheme that allows risky gas development practices. To the extent that the remaining fragmentation results in regulatory dysfunction, though, the current level of integration of authority may still be inadequate.

Finally, these entities have a high level of public and private integration. Industry representatives participate in $\mathrm{RCACs}$, which receive funding from two major corporations. State members of the DRBC also re-

296. Freeman \& Rossi, supra note 36 , at 1182.

297. See id. at 1183-85.

298. See generally COLLIER, supra note 96 , at 1 (suggesting that the DRBC sustains a cooperative climate). 
ceive industry input through an industry-nonprofit group called the State Review of Oil and Natural Gas Environmental Regulations ${ }^{299}$ and indirectly from DOE advisory committees, which publish recommendations for improved fracturing regulation. ${ }^{300}$ Further, NERC's approach provides for utility and electricity end user participation and a private governance structure. Utilities also have a high level of involvement in RTO decisions, and RTOs are themselves nonprofit boards. ${ }^{301}$

Despite progress in integrating private entities within the energy governance schemes discussed here, it is often unclear if their mechanism for structuring public-private integration is optimal. Commentators, for example, have raised concerns about capture by interested corporations in multiple instances, and some of their proposals for further reform could improve these institutions. For instance, Plater's critiques regarding RCACs reliance on interested corporations for funding and cooptation of their board members suggest further strategies needed to prevent capture; ${ }^{302}$ RCAC funding could be restructured so that a more independent entity allocates the money, and more oversight of board members could take place. Although issues of potential capture cannot be fully eliminated so long as valuable private party inclusion occurs - and additional structures to ensure independence can create structural inefficiencies and reduce effectiveness - continued reassessment of these institutions' approach to private integration seems critical.

As in our substantive assessment, we are cautiously optimistic about the governance innovations seen within the institutions analyzed in this Article as a strategy for better governance approaches across energy law. These institutions are not panaceas, and our case examples reveal many limitations of hybrid regionalism, even in substantive contexts where the underlying geography of the problem lends itself to regionally-based approaches. Regional-level entities at times cannot fully address issues that occur primarily at state and federal scales. Multilevel, iterative processes are messy and do not always reach conclusions that satisfy all stakeholders. Public-private hybrids must always be alert to concerns about industry capture. In addition, because these institutions and their innovations often emerge from crisis, their approaches may at times be hard to replicate in other contexts without the regulatory push that crisis brings. Even with these limitations, the institutions discussed in this Article serve as an important model for the road ahead. They demonstrate the possibilities for hybrid, regional institutions to address the physical and

299. Past Reviews, STRONGER, http://www.strongerinc.org/past-reviews (last visited Oct. 28, 2013) (showing that the organization has completed reviews of hydraulic fracturing regulations in six states).

300. See, e.g., SEC. OF ENERgy Advisory BD., U.S. DeP'T. OF ENERgy, Shale GaS PRODUCTION SUBCOMMITTEE 90-DAY REPORT (2011), available at http:/www.shalegas.energy. gov/resources/081811_90_day_report_final.pdf.

301. See Regional Transmission Organizations, Order No. 2000, 89 FERC II 61,285 (1999) (codified at 18 C.F.R. pt. 35) (noting that "Commission-approved ISOs operate, or propose to operate, as non-profit organizations" and include "both public and non-public utility members").

302. See Plater, supra note 106 , at 660 . 
governance-based complexity of the energy system in a principled fashion as our institutions strive to respond to substantive energy challenges.

\section{VII.CONCLUSION}

We are still far from achieving needed energy transformation in the United States. Part of this Article's goal has been to explain why such change is hard and what it would take to get there. As we observe in Dynamic Energy Federalism, we cannot solve our modern energy problems without grounding governance approaches in an understanding of federalism that acknowledges and embraces the underlying complexity of the system. Simple solutions that involve empowering one key actor at one level of government are unlikely to work without massive-and likely politically impossible-reform of the law applicable to energy at multiple levels of government.

This reality does not mean, though, that the goal of energy transformation is impossible. This Article provides case examples of dynamic, hybrid entities to show how institutions can be structured to navigate the governance challenges arising from complexity. The institutions described here offer limited examples of a much broader set of energy governance institutions, omitting, for example, state energy siting boards that draw together municipalities and state agencies in streamlined processes $^{303}$ and interagency coordination to address offshore wind development. ${ }^{304}$ They provide, though, a taste of the extent to which integrating actors from several governance levels, coordinating regional approaches among these governance levels, and enabling unique interactions between actors-including public-private cooperation - offers promise for future energy transitions. Their method of approaching our complex energy system, and the resulting gains and pitfalls, can assist future efforts in these contexts and others to structure needed innovation.

Specifically, as analyzed in Part VI, the entities studied in this Article embody our proposed principles for effective governance in several ways that could be replicated in many other substantive areas of energy law and beyond. First, they focus around an interstitial governance lev$\mathrm{el}-$ in all of these cases the regional level between state and federal. This "in-between" scaling allows them to more effectively navigate the

303. See, e.g., ENERGY FACILITY STTE EVALUATION COUNCIL, http:/www.efsec.wa.gov/ default.shtm (last visited Oct. 28, 2013); see also generally Hannah J. Wiseman, Expanding Regional Renewable Governance, 35 HARV. ENVTL. L. REV. 477 (2011) (discussing these and other unique regional institutions).

304. See, e.g., Secretary Salazar Announces Approval of Cape Wind Energy Project on Outer Continental Shelf of Massachusetts, U.S. DEP'T OF INTERIOR (Apr. 28, 2010), http://www.doi.gov/news/ doinews/Secretary-Salazar-Announces-Approval-of-Cape-Wind-Energy-Project-on-Outer-

Continental-Shelf-off-Massachusetts.cfm (describing negotiation between the Dept. of the Interior and the Advisory Council on Historic Preservation); U.S. DEP'T OF INTERIOR, Cape Wind Energy Project: Final Environmental Impact Statement, OCS Pub. No. 2008-040 (describing review and input in the approval process by the Dept. of the Interior, the Coast Guard, the National Marine Fisheries Service, and other agencies). 
fragmented and inadequate authority in the key levels above and below. Second, they do not simply attempt to create new governance authority at that level, but also use their regional scaling to help combine existing authority at multiple levels. They include key stakeholders in those interactions, including those who lack top-down authority. Finally, they incorporate all key stakeholders, not just governmental ones. Their inclusion of corporations, nongovernmental organizations, and individuals in formal processes helps governance reflect the underlying relational dynamics more effectively and often makes the difficulty of navigating capture concerns worthwhile.

Combining the governance model offered in Dynamic Energy Federalism and this Article's practical applications of this model to modern energy challenges will provide important lessons for institutions moving forward; indeed, hybrid regional institutions, as opposed to unilateral state or federal approaches to energy issues, likely should be the new norm in energy governance. Not all institutions will need to be regional as they attempt to integrate these principles; all of the energy challenges that were the focus of this Article, from the reliability and expansion of the transmission grid to drilling gas wells in watersheds and oil wells offshore, had clearly regional impacts and implicated a range of actors. Certain energy issues will be more compact both in their effects and their planning demands; distributed generation such as solar panels on roofs, for instance, may require primarily local zoning governance. ${ }^{305}$ But even in those cases, some multilevel interaction takes place, which could make some variation among these governance approaches valuable. For example, distributed generation has system-wide impacts; if the majority of residents in a neighborhood installed solar panels or wind turbines in backyards, they could potentially exceed the local capacity of the grid, or could-if policy allowed-join forces to form a larger generating unit that affected the larger transmission grid. ${ }^{306}$

Similarly, public-private integration should take a variety of forms depending on the energy issue addressed. Many institutions will not need the level of private involvement that, for example, NERC requires. Whereas utilities are necessary players in a governance regime that writes and enforces highly technical standards for the reliability of the grid, governmental actors may have sufficient knowledge of, say, certain risks of oil and gas extraction to do most of the governing themselves. There, too, though, exist detailed and long-tested industry standards, and as technologies for unconventional extraction rapidly change, industry may hold most of the key knowledge of risks; the aftermath of the BP Deepwater Horizon oil spill reinforces the difficulties that superior industry information and access, paired with regulations that struggle to keep

305. See, e.g., Garrick Pursley \& Hannah Wiseman, Local Energy, 60 EMORY L.J. 877 (2011) (arguing for local governance of distributed energy installation above a federal floor).

306. See, e.g., Sara C. Bronin, Curbing Energy Sprawl with Microgrids, 43 CONN. L. REV. 547, 571-72 (2011) (describing opportunities for microgrids and policy needs). 
up with technology, can provide for regulators attempting to respond appropriately. Each regime will have to weigh these and other questions, examining the need for cross-cutting regional governance, industry involvement, and enhanced stakeholder participation in that setting.

The governance experiments described in this Article do not immediately solve all challenges by virtue of their innovations. As each of their stories reflects, these institutions all have faced and continue to face obstacles, and they arguably each have an uphill battle in achieving needed substantive change. But even with these difficulties, they help provide hope and a way forward. They demonstrate the possibilities for operationalizing needed dynamism in the complex energy system and the transformation that can result from doing so. 